2. D. B. V. De.

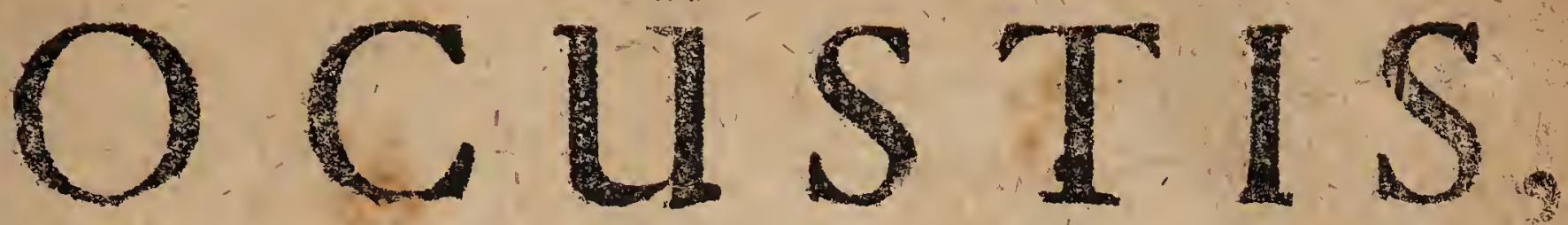

IMNENSO AGMINE AEREM NOSTRVM IMPLENTIBVS, ET QVID PORTENDERE PUTENTVR,

Numine Aternoadpirante in Academia Fenen?

\title{
SUB PRAESIDIO
}

\section{OH.PAVLIHEBENSTREITI,}

Moral.ac Policices Prof P.Ordinarii,

d. XXVI, Aug. MDC XCLII.

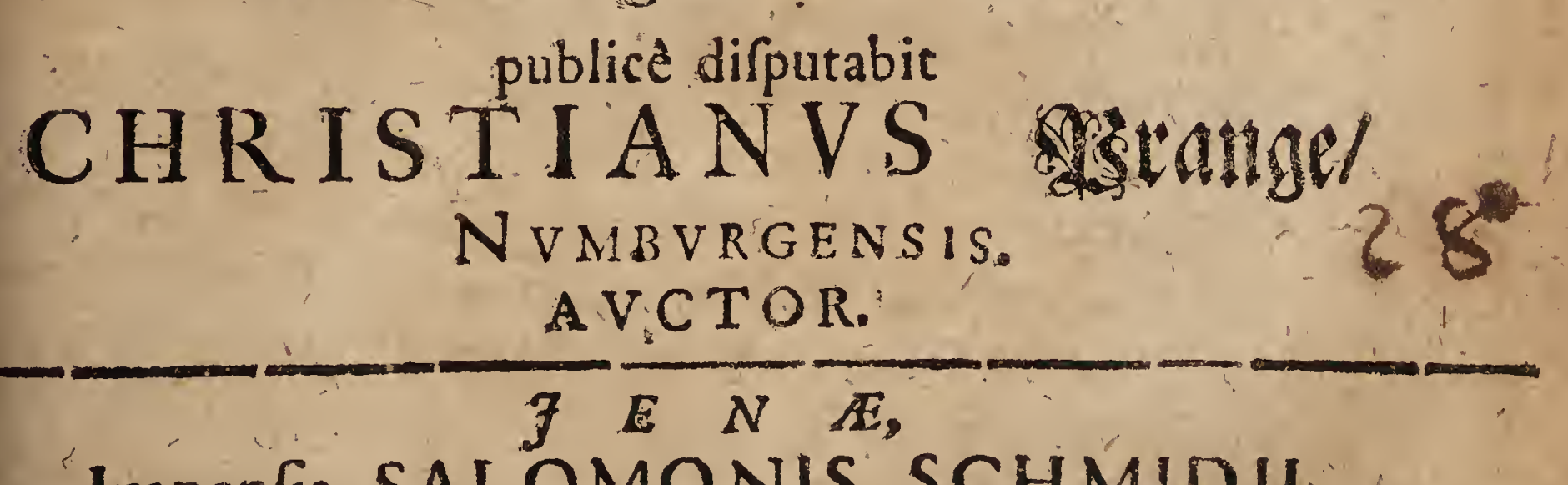

Impenfis SALOMONIS SCHMIDII:

Literis KREBSTAN\&S。 


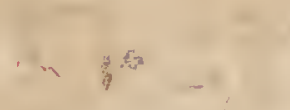

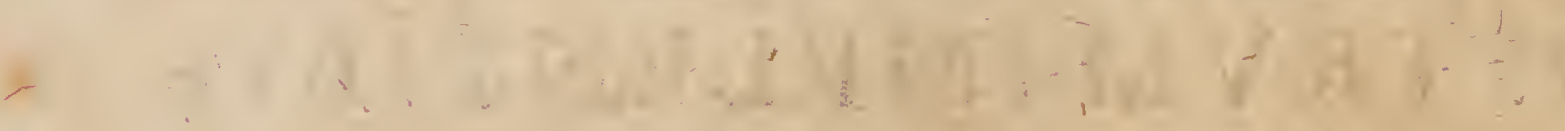

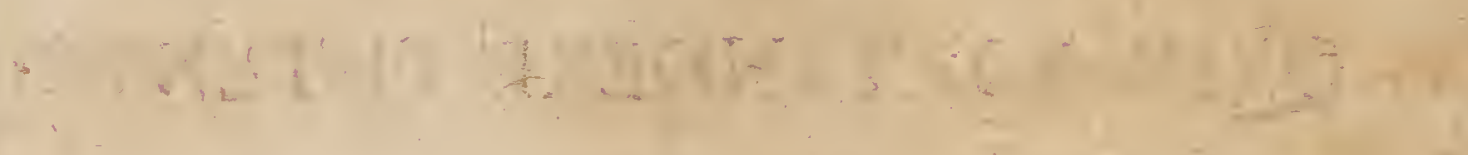

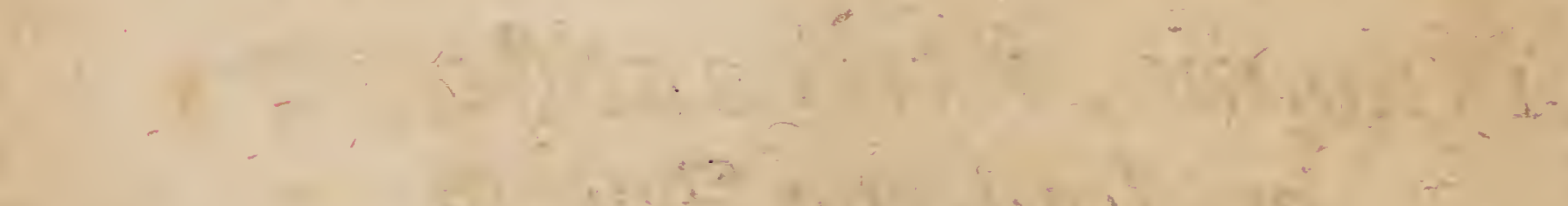

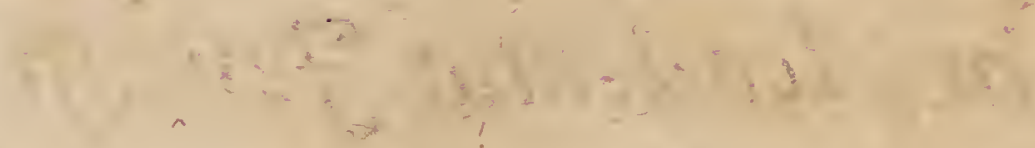

$-$

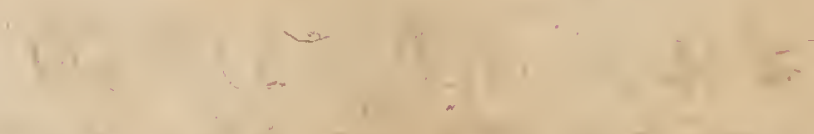

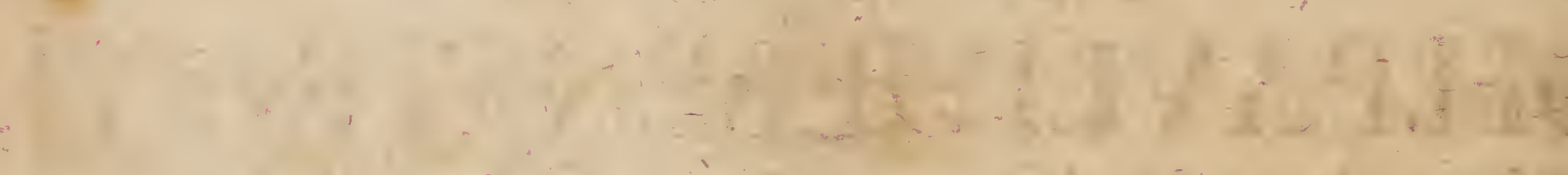

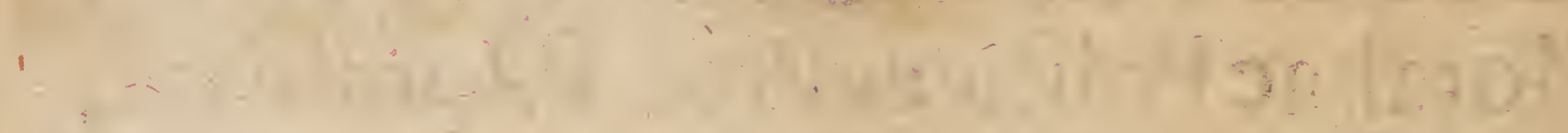

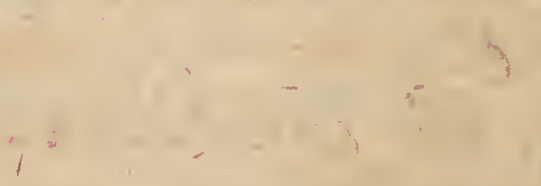

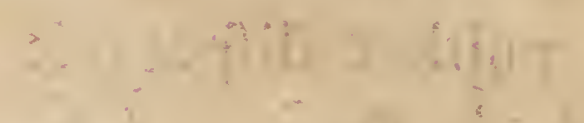$$
15-1,1,2
$$

\section{3}

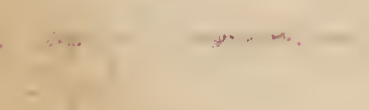

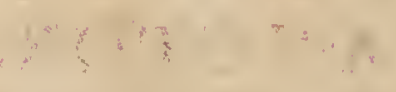

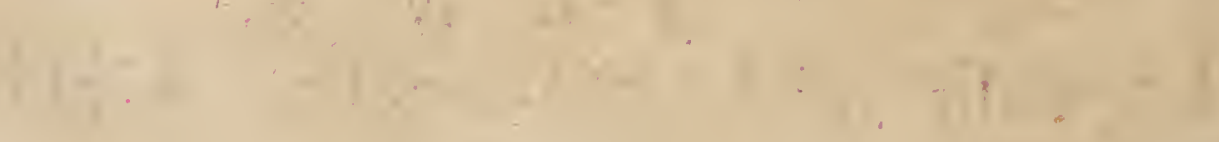




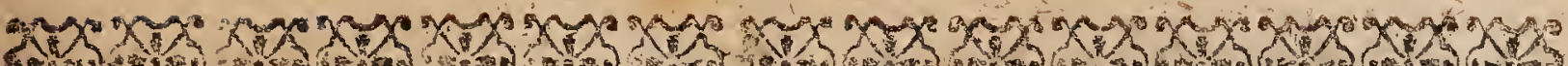

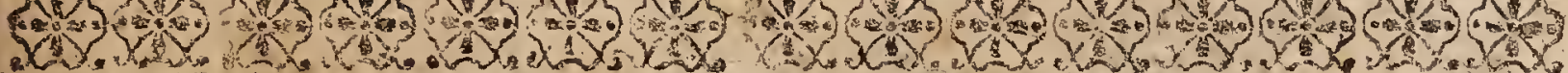

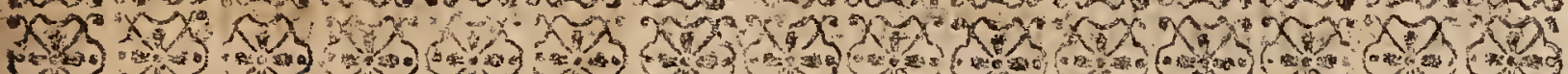
(a)

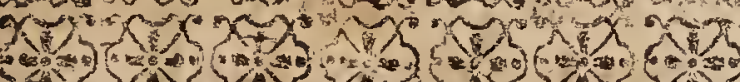

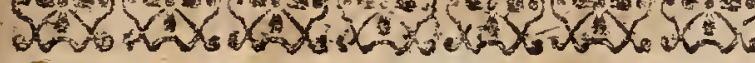

\section{I. $N, D$ \\ Prolegomena.}

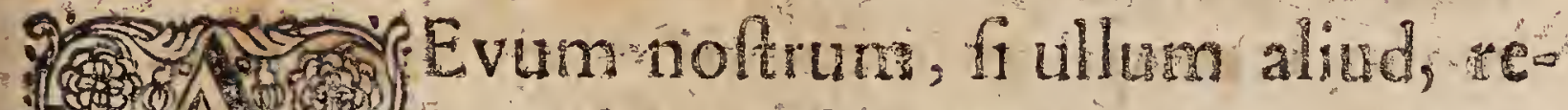

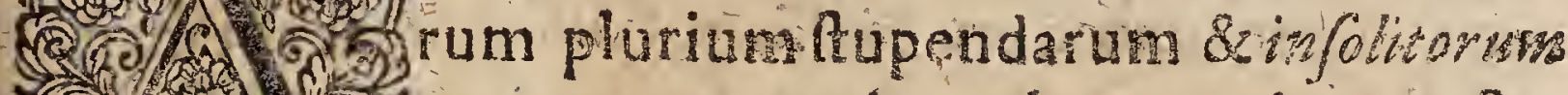
9. -1. - eventuum nomine ad memoriam pofte(1) Writatis infigne eft: Obverfaturadhuca. 20. ni Turcarum agmine obleffe, ac barbara horrendaque rabie impugnatz: Pradicamus meritò nunquam datam aliès fortunam Chriftianorum, qvi paucoruna annorum decurfu tot regra, tot infulas ac ditiones, Hungariam, Moréam, Tranfylvaniam, ac provineias alias à Turcarum, qvorum infregere robur, impotenti dominatu liberarunt: Conftat omnibus, quàm incredibili felicitate IVILHE LMVS III.virtute pariter ac fortunâ excellens Rex, procellofi temporis difficultatibus, \& intumefcentis freti fluctibus fuperatis ex Hollandia oris trajecerit in Angliam, regnumque iftud ampliffitmum flor enrifimumque contra tot Gallorum ac Pon Lificiorum clandeftinas molitiones, quibus acerbifimaservitutis jugum imponere, pracipuè auten tefor: matam religionem ab aris, à templis avertere longê. nyin ex ip fis evelle mentibus nitebantur, afferuerit, e. 
Cis locutis illis pernitiolis $s^{3}$ fefuitis, quinefcio à quo Lojola inaufpicató partu editi, \& in exitium commune finiftrâquorundam liberalitate educati, in copias innumerabiles, locultarum inftar, qua totum fxpè annumeverunt, increvere. Horret animus cogtatione rerribilishllius terra motus, quó, vergente feculi la bentis anno nonagefimo, urbs noltra \& tota feré con. remuit Germania, \& conqualfata fuit. Innotwit fa. molus acmortal um memoria maximus terrat mocus, qui nuper admodum Siciliam concuffi, ac to tam prope lua vi fubvertit, Atrocius certé eft, ac latus funditur malum iftud, quàm vehemens illa Siciliz con. Cunio; a Thoma Fazello (a) defcripta, quâ anno 1169. menfe Februario urbs Catána usque adeo convulfa fuit, utronadificia modo omnia, fed viros quoque ac mulieres circiter quindecim millia cum Epilcopo maximaque monachorem parte ruina opprimerto Paucisadhinc diebus res nova ac vifu ftupenda, qua haudfallas mali imminentis praragum vulgo cenfep tur, Jenx, \& in agris vicisque ipli crreumjedis in o mniumoculos incurrit, animosque attonitos ingent horrore perftrinxit. Die labents menlis decimo

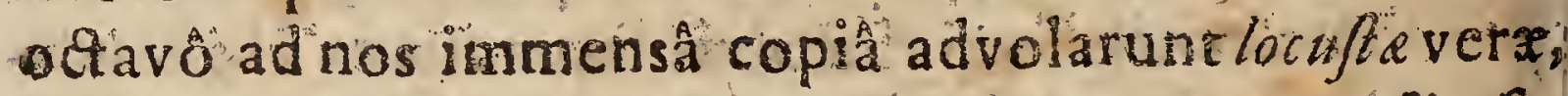
nobis nunquamaliàs vifx, à cicadis per pratanoftra ra. liencibus, planeque inutilibus \& innacuis, ipsâfpecie ac qualitate prorlus diverfa, lisque, fil folam (qua etiam preter auctoris mentem a pichore auda fuitjexcipi. asmagnirudinem, plane Gniles, quas Rabbi udnanias zezanus è Maritan aveniens ibidem reperiri $\&$ at jncolis

(j) Dereb. Siculo.Decad. griós libr. Ir capa IV". 
6.

Gis, ita inharebancterra noftre utnuliô frepitu con citató, nullâ viabigipoffent ae propulfari. Vui altas yapore folis accenderet tellurem, \& die fervidinmum cempus elle inciperet, tum demum in fublime vele. bantur. Cuin alfurgerent, acfefe alarum remigio ef. ferrent, hinc ad alios: Thuringiz tractus commear. ses, ab hora nona antemeridiana-ad quintam usque po. meridian qua acie infructa turmatim provola. bant. Quandoque tanta earum nubes fe intendebat colo, ut folem quadantenus obumbraret, ejusque ni. corem ahiqu modo conderet. Tàm denfum agmen aërem noftum implebat, ut columbas, aliasque avicum las colum trajicientes fuffla minaret, ac mole fuấrup. primeret. Gregatim fublata tanto pennarum frio done frovebant, ut precipitis aqua ad arperos lapi des allifæ, ac perfaxadecurrentis aur ventiarbores qua. jrentis Conumredderent. Avium certè velocitatem volatu fuo aquabant, \& magnà pare templorum noArorum fanigis fupervolabant - Agmina quadam in feriora in oraperegrinantum ita irruebant, ut baculo nunc huc, nunc illucvibrató arcenda effent atque fusanda, isque montumac parum vicinorum conSpectum obfcura fua nubeadimebant. Mula in pla was ùbis, tedtaquenotraincidebant, ut paffim à pue is caperentur. Atque hac locularumin nofras teras Illatarum innumerabilis copia apudnos cajus valde in. folitus en, ruti eam Menochins (c) appellitat) h.e cafus adeo rarus, ut non potuerit verolimiliter viro prudente cogitari: Nec enimhominum memoriâpelís e.

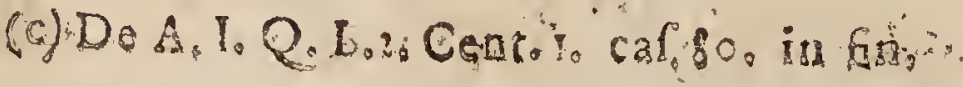



Lociustamim

numer inofrü aera jervantuim.

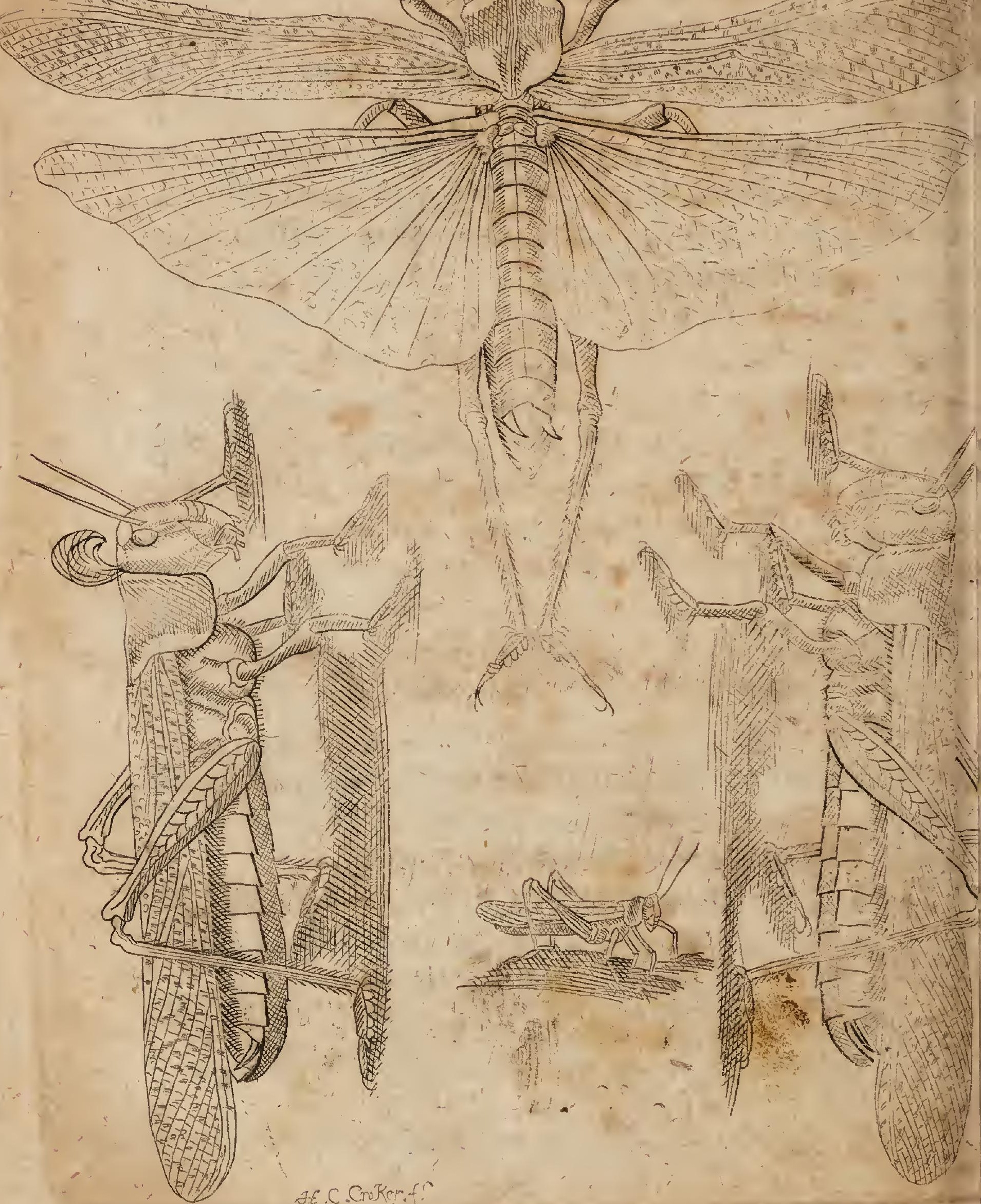


justriodi noftros tractus infeftavit. Franzius (d) eqviz dem teftis eff, locuftas longos venures \& in capitibus co. ronulashabenies, ac tetrum odorem exhalantes anno

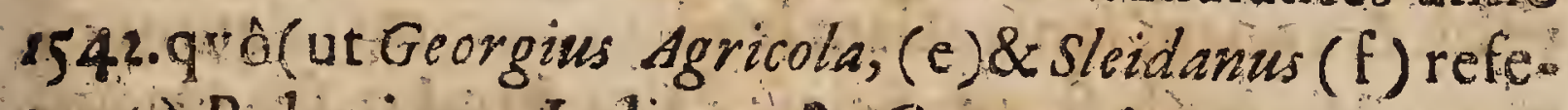
runt) Poloniam, Italiam, \& Germaniam peryagate funt, in Silefiam quoque, Lufatiam \& Mifniam irruiffe, \& alicubi in Marchia ad equi ungulam usque jacuisfe, aft ab illo tempore dirum iftud infeQum tantầ vî ad Thuringix ac Mifnix oras effe provectum, legiffe me vel audivife non memini. Unde quod Menocbitive olim 1.c. Tcripfit : Ego aliquando refpondh, cafum fuife valde infolitum, cum in Italiam advolabit inmenfa illis Locuftarum quantitas, que in bâc regione bifa of tongs. quam, vel fivifa aliquando oft, jam mille elapfis annis bifa eft: Et licet cogitari potuerit de Locufis, ut in L. Excepto C. Locat. non tamen de tam ingenti quantitates quäm illa fuit, que advolarit eò an is 42 ; idem de locuIftis, fi in tanta multitudine ad nos adventent, pronunciandum effe, Dn. D, Joacbimus Hoppius in eraditiffima quadam differtatione $(\mathrm{g})$ fcite monet. Ex hoc verò, quod locuftx immenfis ejusmodi turmis advolantes fint res valdè infolita, nechominum memoriâ vifa, præftantiffimi Jurium interpretes concludunt porrô, conduciorem, qui in genere omnibus cafitus renunciavit, de edacitate locuftarum non teneri, fed

(d)Hin anim.p.m. \%99. (e) libro de animantibus fubterraneis, grem a Georgium Fabriciumanno 1548. fcripfit (f) lib.XIV. (g) qux ef de edaci Locuftarum pernicie ad L. Excepto rem pore \&. de Losat. \& Conduct. Francofurti ad Viadrum an 1.68\%, habita. 
8.

damnum $a b$ is Illatum detrahere poffe,etiam 1 jur ot îta factafit renunciatio, imò cafos cogitati \& incogiratiline difcrimine fufepti fuerint.Quippe communem velut \& quam fententiam laudant commendantque; quam Mer ius (h) fic enunciat: Dann begeben fith tergleia

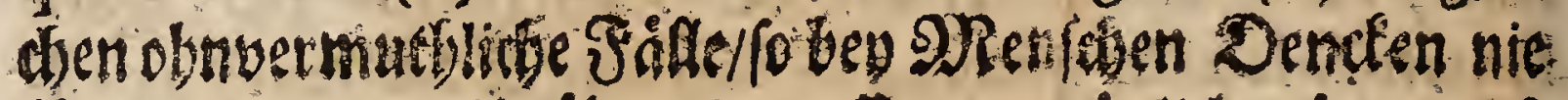

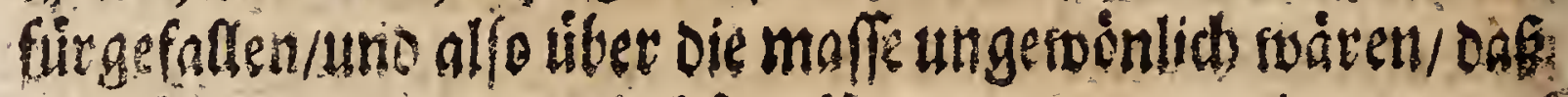

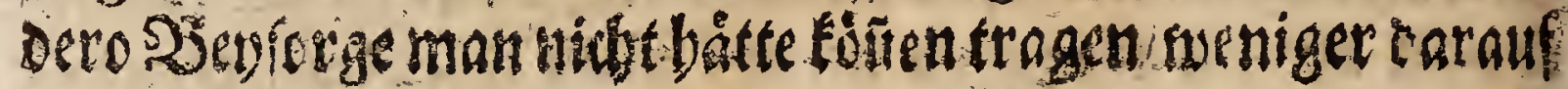
Die (Giecondeten ridsen/ perbleillet es Det Sufpection uno

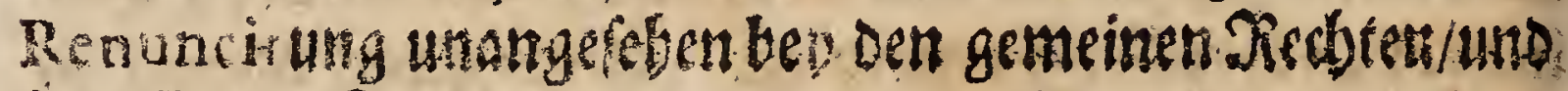
betriffe ier Sdjade sen Colonum nidjt. Neque ipfum juramentum ad non cogitata, feu ad ea, de quibus verofimiliter non potuit cogitari, extendi perhibetur (i). Arque cafus incogitati , quos quis in fe fufce. piffe dicitur, accipiendi funt fecundum prafentem ftatum, non antem de is, gui etiam prudentiffimum vie rum fallunt (k). Caterum ipfe,cium rarum iftud, \& in terris noftris valdè infolitum infedum, cum fudioIns quibuselam attonitus contuerer, acNemereos divina iram adverfus mortalium genus concitatam inde colligerem, de pefte illa atque ejus prafagio publicé differendi impetum, ipfo in hoc tempas congruente cafu. admonitus, confeftim concipiebam. Peritè autem negotii illius partes me neutiguam impleturum effe ar bitrabar, nifi \& paffim de locuftis in univerfum philefopharer, as qua generatim de is prolara funt, fubinde

(h)De Penfod n. 105. (i) Seraphim. de Privifeg Juram. Pivil.ng. n. 2 Adriass Gylman Tom. A. Symphorem. Part. I. Vot.27.n.

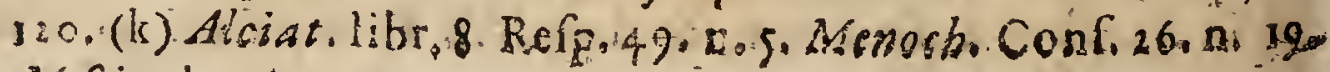
Mation l, c, n. Ing. 
de ad noftra agmina atcemperarem. Ouod argumentum infolitum dum aggredior, Omnipotens Numen, ut propi* tumm miki fit, fupplex oro.

\title{
CA P. I.
}

\section{Nominis LOCDSTAE bo.}

\section{monymiam 8 Ignificationem tra.} dit, Es, quo fenfu iftud noftratious tribue -

\author{
tur, aperit. \\ 1 .
}

- I pro copia rerum fuper loculis in univenfum coma. mentari \& argumenti hujus, quoit tractandum fúce. 1) pi, totam molem exhaurire vellem, tempus \& charta potius, quàm materies, me defcerent. Itineraria 2 reserum naturalium interpretes demirabili 2 oc infecto in. finita ferè tradunt: acipfe Bocbartu in Hirazoso Go od to capira integra de iiscontexuit. Undecx tancamateria. sum ubertateac amplitudine pauca faltem, \&rea quidem decerpam, gux ad locuftarum noftrarum naturam \& effcaciam illuftrandam nonnihil facere videbuntur.

11. Ê autem pactô meam tractationem digeram difpe. pamó, ut rimo in evolyenda nominis fignificatione, ejusq. ambiguitate difpellenda claborem, danceps animalculorumiftorum naturam partescue perlufrem, tortio de af fectionibus varis, videlicet $(a)$ mat $(b)$ locs, unde adventant, squempervagantur $(\gamma)$ fono, $(\delta)$ qubnitate, (e) colore differam, aro decorum viaceficacia, ad quid profine, quidvenoceant, atque hinc de varis adverfa ea remedis exponam, quinio eorum generationem autortum per. $B 2$

vefigem 
veftigem, sextò quid portendere putentur, edoceam, $\&$ ad extremum quid fecundum jus nature circa damnum ab is illatum obfervari debeat, tradam.

III. Nomen quod attinet, varii varias eujus etymo. logias adferunto: Nonnulli quos inter eft Ifidor. (1) à rocibus: langus \& bafta, illud deflectunt, quòd locuftx longos pedes, haftis non abfimiles, habeant. Alii à vo. cabulis: locus sx fare, deducunt, quod a nimalcula ifta non uno in loco fubfiftere, fed hinc inde fubfilire confveverint. Alii à vocibus: locus \& ufus, derivant, quòd locufta agros, quos invaferunt, wrant, hie: affligant, feu malè afficiant. Eockarto in Hievazoico part, poft. lib. IV . . V. locufta non aliunde videtur, quàn àlocusione appellata, cùm tàm loquax fit, quàm cicada, quam volunt loquacitatis effe fymbolum:

IV. Undecunque vox illa originem habeat, qua. tuor potilimum ejus fignificationes deprehendimus. $A$. dianus Tumb (m) ob fervat, antiquum quendam Cirticum vocabulum hocce ufurpare pro inftrumento ad delendas flañas comparato, qyod altifimè aquam hamaium 8 dolabrarum more evomebat. Nonnunquam nomen ifrud defignat certum herbarum genus, de quo Mattb.Marm tin. in Lexic. Philol, h, voc. Quandog; denotat sertum quoddam pifcium aivasuav (bi e.exfangatizm) genus, quod

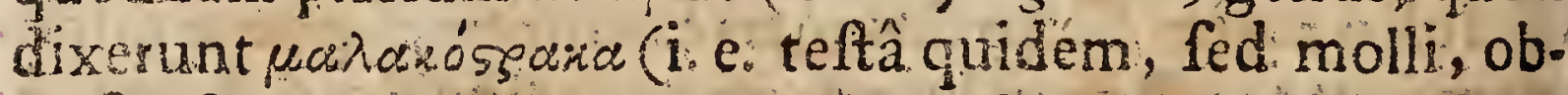

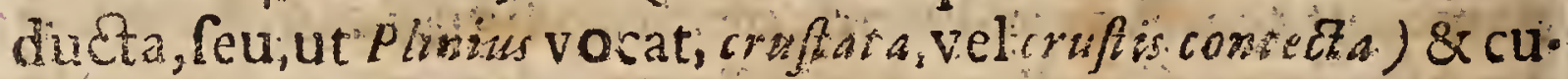
jus quatuor effe fpecies, locuffas puta aftacos, fautlias \& can cros, referunt Arifoteles (n) Esiabenelus (o) Quanquam. (quod obiter hic notamus) plinisu cancrum (ragrivov) non accipiat profpecie carabis contradiffindtâ, fed pro genere aliquo cavabos \& aftacos, velut fpecies, fub fe com8rohendente. Sic \& 7overali (p) \& Romanorum alis la. xius

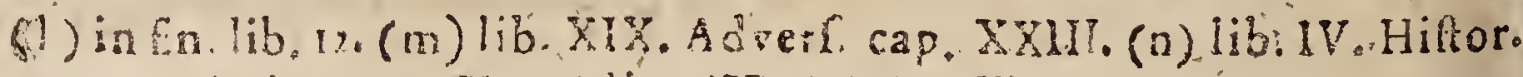
Ansu.cap.I!.(o) lip, II (p) Sar. V. 
xius accipitur fqulle vocabulum, ut noh moso sa édo" fed etiam aliam pifcium ávaluw \&ucinanosénwi fiecien. v.c. a'şaicu, complectatur. Caterum locuftze fenfu, qui ll. cit apud Arifotel m (q) \& Atbenetm $r$ )occurrit, in tellecta vocantur Grace naebob, parteque corporis anterioririgent, ac binis praliantur cornibus, \& utrinques praditi funt pedibus quinis, atque tefte $P$ linió (s) in mari Indico quaterna cubica implent. Iisdem usque adeô capiebatur Callimedon orator, ut tofte Arbendo $(t)$ exinde $C_{a-}$ rabinomen nactus fit. Hôcautem fenfu vox ifta ufur. patur apud spetinitm, qui in vita Tiberil Neronis narrat, Cafarem illum crudelem pifcatori cuidam, qui ipfi fecretum agenti grandem mullum inopinanter obtuleratsperfricari eodem pifce faciemjuffife, \& gratulanti inter ponam, quod non \& locsifam, quam prograndew ceperat, obtuliffet, locufâ quoque lacerari os imperâfe Geminô fignificatu locufe vocabulum adhiberus a pud saffym, qui de Lufitanis in arce Indica Cananor obfeflis \& fame presfis fequentia (u) fcribit: Ip fonit fefio afjumtionis ( $f$. Mariz Virginis) ate, ne qud wiraculo rem yeffet eximere, folito pebementius intumeferis pelagus, ingemen locufte numerum ad ip fas uempliradices ejecit, quie a Lufiranio gnatulabundis avidè col-

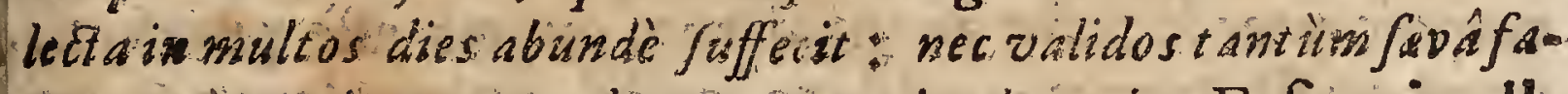
me, verürian gros disturno morbo levavit. Etfi enim IIlütris Ludulfus in ipfa Hiftoric Etbiopica (x) hunc Maffeji locum de terreftribus $\&$ volatilibus locuftis accepiffet, tamen à Clarifimo W. Ennefo Tenzlio, multalectionis \& varix erudionis Viro, admonitus, \& a gobanne Barrio, $\mathrm{Hi}$ forico Lufitano, eandem hiftoriam enarrante, rectius in. ftruetus, eum pofthacin commentario fuo $(y)$ de locuftis marihis inérpetatur.

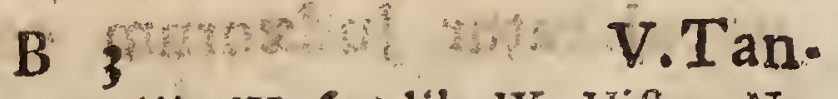

(q) lib. IV. Hiftor a nimal cap. II (s) lib. III. (s) lib. IX. Hiftor. Natur.c.IY. (r) lib. IIf. (u) Hiftoriar. Indic. lib.III. (x) lib. XIII. (y) P. 18. 18:. 
V. Tandem locufas vocabulum notas infectum aliquod \&erreftre \& apud nos infolitum, frugibus inprimis perniciofum fructusque ac fegetes adurens \& confumens quod Gracis communiter àeis dicitur. Qux explicatio etfi locuftan, (quippe qux ob nimiam fuam diverfitatem ex. quifitam definitionem refpuit)accurate fatis non definiat, difcernit tamen eandema a cicsdis per prata nofira quotansis falientibus, utpote qux parum detrimenti frugibus adferunt, cùm folùm in gramine degant, \& pruina five rore contenta fint.

VI. In uitimo hốc fignificatu Locufte nomen fortiuatur animalcula ifta, de quibus in prefenti fpecimine philofophamur. Enimverò nec vocem illam hoc fenfis ufurpatam, \& infectis quibusdam tarreftribus attributam, a eam latitudinem extendimus, ut fub fe complectatur. quoquelocuftam ämeg" (h. e. alerwin expertem), fed hic cum maximâ fcriptorurn parte ad eum acceptionis gyrum revocamus jut aliquod apud nos in folitum, terreftere, volatile, frugibusque inprimis? perniciofum infeetum defrgnet. Caterum locufta guxdam a'mep (3) eft ca, quz apud

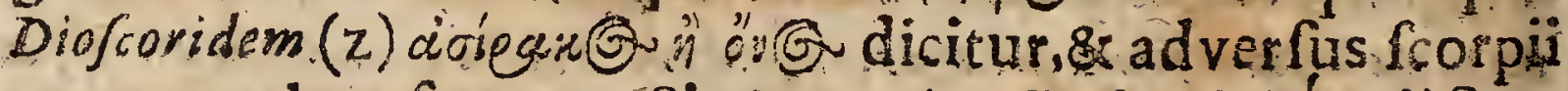
venena communiter locuftx genus alarum expers effe putatuc, quod è fit maximè peftilens, quòd, quia volare non po. tent, regionem illam, ubi confedit femel, totam interdum populetur, atque urat. Solere autem Brucbos, cum avolare non poffnt, comprehendi, \& illorum acervos conjectos in follas terrâ tegi atq; opprimi, colligi iur ex E.

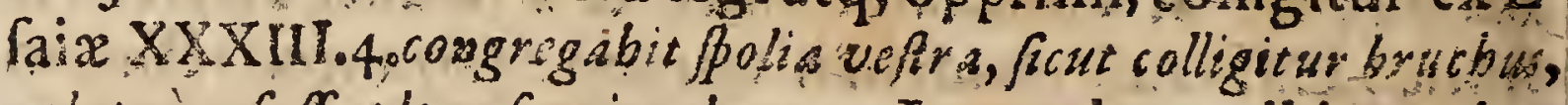
xelut cim foffeplene fuerint de co, Loquebatur ibi Propbche de Senacherib, cujus exercitus ficut bruchorum multitudo populabatur Judzorum regionem qui tamen in so

(2) libr, II Mater, Medic, cap. UXXIY。

pheth. 
ris.

pheth; quafi in foffas bruchiconjecti,oppreffus eft Quari quam fint, qui bruchos effe autumant illud vermiculorum genus, qui vites, cùm germinare incipiunt \& fruetum ftendere, cortodunt:Id quod fortaffe verum effe, Cafpar Sanctius in comment.ad cap. I. Joel, arbitratur. Eft $8 \mathrm{im}$ A merica alia inter Locufas co rógs fpecies, qua Gracis Montis, L atiuis vates dicitur, quod, ubicunque appareat, macra fit $\&$ famem portendere perhibeatur. Refert Gut Lelmus Pifu (a), eam inuftatz fgurz ac naturz efre; prio. respedes inftar brachiorum junetos \& quafi manus ad colum elevatas habere, ut credant fuperftitiofi incola. quod homines fupplices ad coelum palmas tendere do. ceat ; ac cerfo quodam tempore, veris vicem fupplente, vitam fenfiti vain derelinquere, \& transformatam aliquandiu in plantam, tandem more caterorum vegetabilium márcefcere. Urut igitur locuftx nomen, quatenus infea tam aliquod denotat; animalculis quoque alarum expertibus tribuatur,tamen ex ufu loquendi in Phy ficorum, fcho-

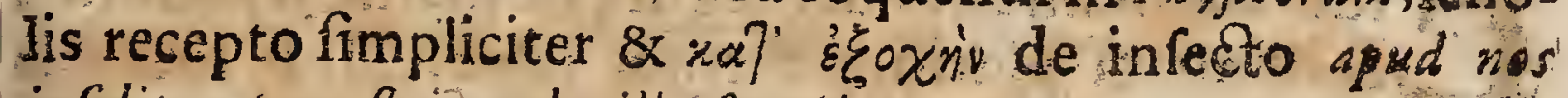
infolito, terreftri, volatili, frugibusque imprimis perniciofo dicitur. Unde \& cum apud Atsanafum Kircbertum (b) all-

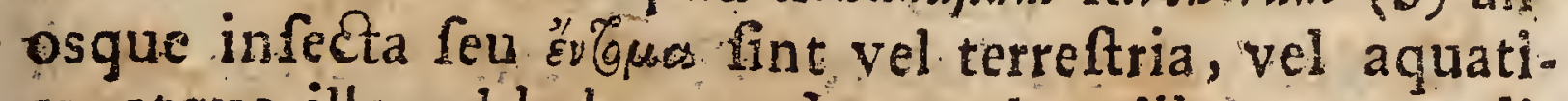
sa, atque illa vel habere pedes, vel pedibus sarere di. cantur, \& qua pedibus inftrueta funt, vicifm diftinguantur in alata, \& alis deftituta, Locuftx ad infectaw cerreftria, pedibusque $\&$ alis prodita abfolutè referuntur.

VII Hic autem non poffumus non notare Frideris. sum spanbemism, (c) qui Locuftarum, ut fune animalia ex. infectoram genere, diverfa inquirt effe nomina apud $\mathrm{Gr}$ \%

$\cos$

(a) de Indix utriasqquere natura li \& medica Lib. V*cap.XXI.(b) Mund.

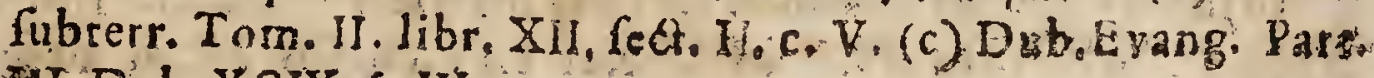
MI. Dub, XCIX, .,III, 


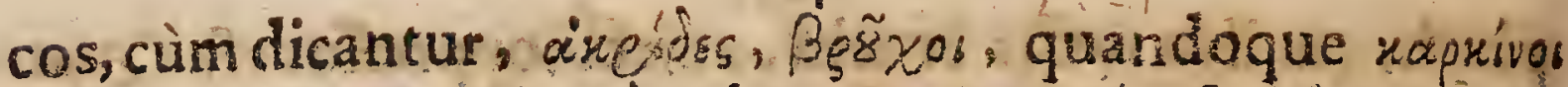

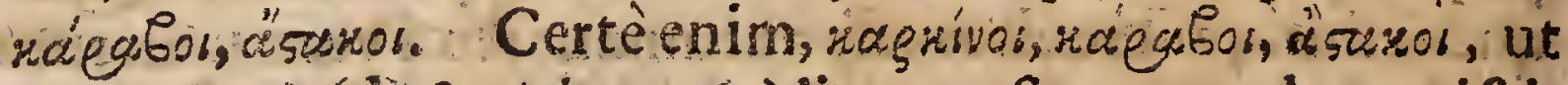
ex Arilocele (d) \& Atbermeo (e) liquet, funt quxdam pifium fanguinis expertium genera, qux ucì arósgara, feu,

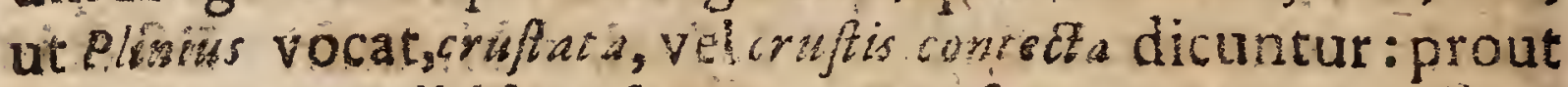

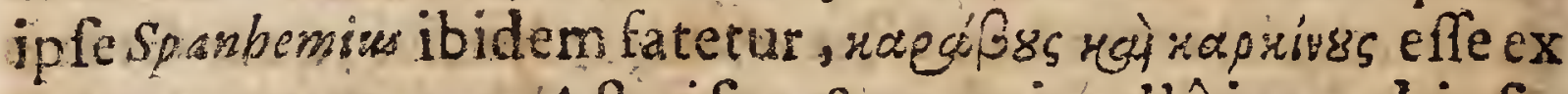
cancrorum genere :'Aft pifces \& cancri nullôjure ad infectoruin claffern revocari poffunt.

\section{Caput II. \\ LOCUST ARVM naturâ Partibus.}

I.

TXPlinio, $(f)$ liquvet, tàm validam firmamq; locufta. rum naturam effe, utlonginqva maria tranfeant, continuatâ plurium dierum fame. Ip fe locuftas aliqvot nuper inclufi vitro, easqve per feptem dies fine ullo alimento vixiffe, experimentô didici.

11. Non videntur habere noftre locuftre nervos, nec offa, necfpinas, nec cruftam quidem fragilem, nec qux jure dicatur cutis, fed partes medix cujusdam inter omnia hæc natura, cof pus arenti finile, nervô mollius, in reliquis par. tibus faccius verius, quam durius. prout $P$ linius $g$ ) de omnibus infectis pronunciat. Imò id ipsũ, quô cohærent, non inter offi 8 cartilaginem, fed, cùm molle fit ut caro, diftendatur autem ut nervus,inter cartilaginem \& nervum mediã nàtúram habet, utijudicat Gerardus foannes VofJuis(h). Cùm enim

(d)lib IV.Hii Yor. A nimal.c. II.(e) lib. III. (f) lib. XI. Hif. Natur. cap. XX'X.(g) lib. X!. Hit.Nat.c.IV.(b) lib. IV. de orig. \& progs. idololatr. cap. LXX. 
Profer in fententix illus Ludolfina dilquiftone MSta Equam Illaris Ludalfus proincomparabili fua erga me be nevolentiâ benigne mihi nuper huc tranfiens communi cavit] ut probet, vocem , fW Num.XI. 3ro quam vulgata reddidieper cotumicem, proprè avemaliquam, \& non lo. cufam notare objicitdifertè, carrzem propriè dictam petiffe

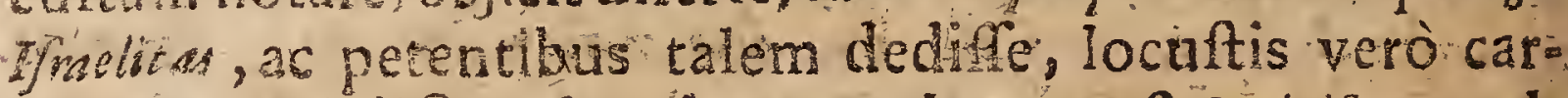
nem propriedicam haud convenire. Aft tudfus excel. lentimus in animadverfonibus fuis ad diffuiftionem Iftam manuforiptis, qua omni rarifima erudionis copin referta funt, repondot, probari fufficienter haud pofe, quod Deustalam carnem dederit, qualen petierantifrae litx, velin animo habuerant, cùm nec panemillis dederit, qualem concopiverant, fibique fuerant imaginati. Unde \& cenferguod, quemadmodum Deus panem pofcenti. bus allouid pani ávé $\lambda$ ozo\%, largitus eft, ita flagitantibus camen aliquid ei fimile \& analogum dederit.

V.Utum auten Hac locufarum noftarum caroifiv propiè; frveanalogicè fic diea, cibus infalubris fit, difqui-

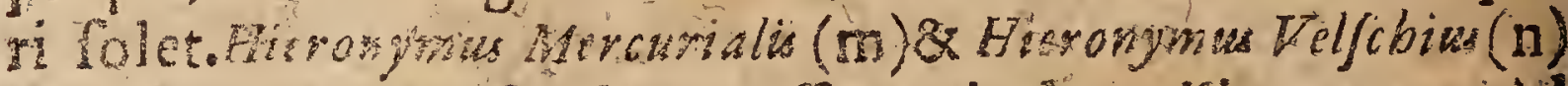
locuftas efcam infalubremeffe, exinde colligunt, qvod

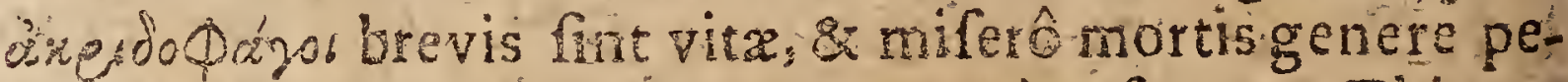
reant. Quippe Sirako (o) \& Plariss (n) referunt, Whiopes

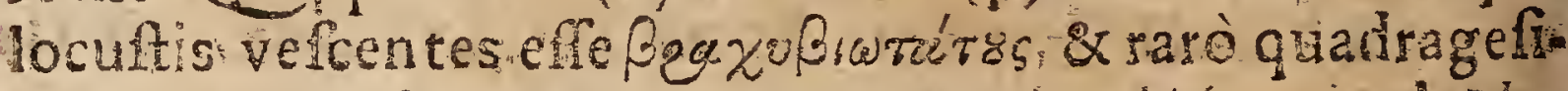
mum annum fuperare. Atque Agababides apud Bbo tum (ब)perhibet, whiopes locultis victitantes mifera* Bili more poft quadraginta annomm decurfum decede te. Teftatur enim palam, quod, fmulatque fenium apgropinquat, innafcatur E thiopum illorum corporibus vo Jucre pediculorum genus, quod insipiat à pectore 2 al

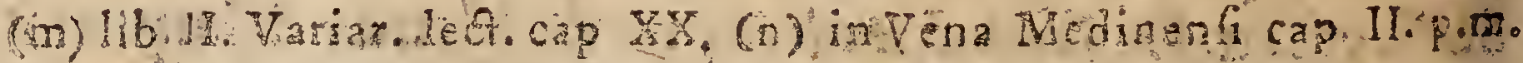

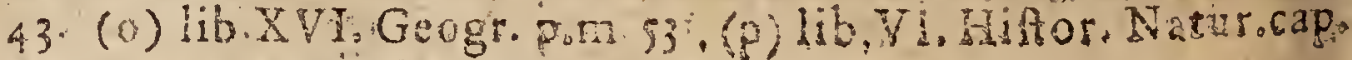
XXX. (q) Bibliosh, Cod CCds 
vo, continuo autem unà cum facie onnem couporis fu perfoiem depafcat. Hocidon feredt, quod de llis st.

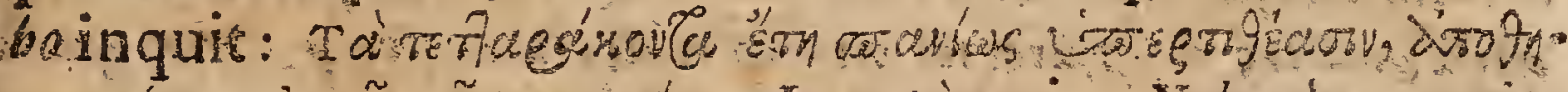

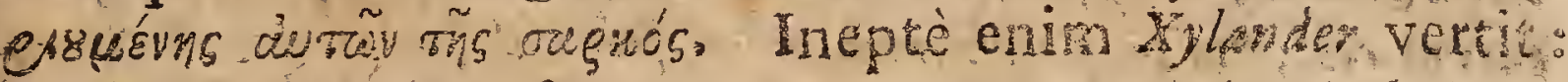

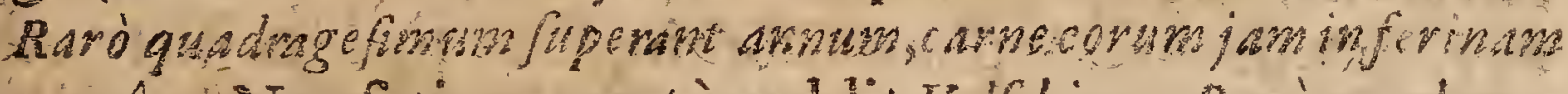
gersâ. Nec fatis accuratè reddit Velfbius: Raró quadrage

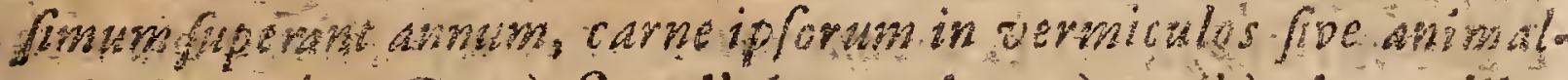

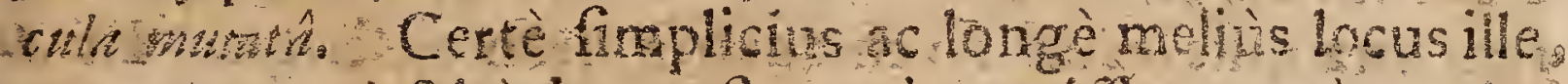
ut Ludalfus (r) foite docet, fic verciporuife: : Rarò quatho

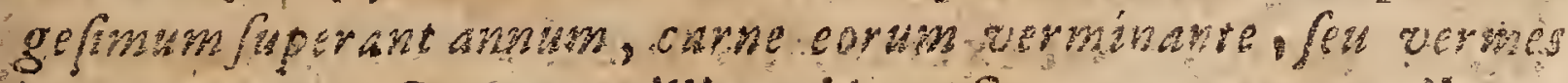
progignexte. Cxterumilli, quilocufrum carnem cibum infalubrem effe credunt, caufam brevioris hujus vies asm

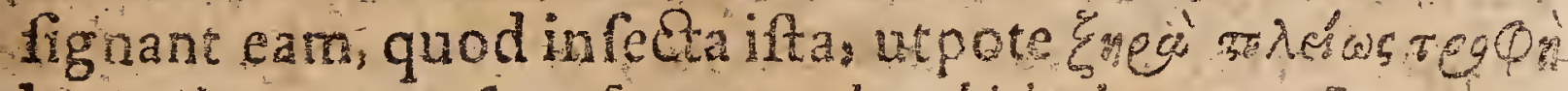

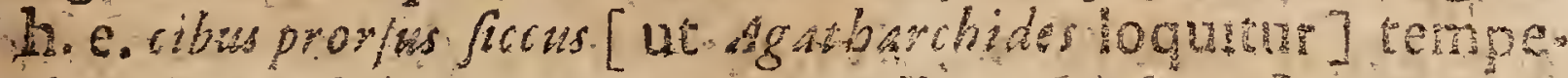
rien paularim cormmpant. Alicontra locutarum car. nem in facper fehaud efe infalubrem pertenduns, efi per accidens, frempe quis aimis ac perpetuo eam comedat. nocere ipla as temperiem corrumpere gueat. Manife fè Uly fes Aldrouns dus (5) locuRas ad medicamenta utiles pradict, ac Mofer in felgendis cibis dibentimum cas

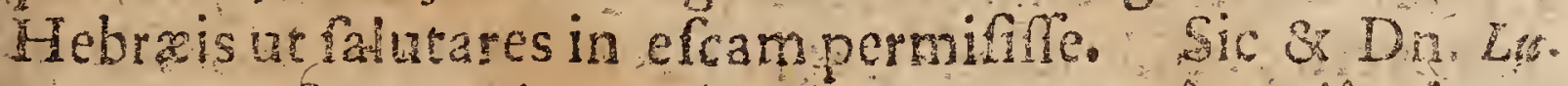

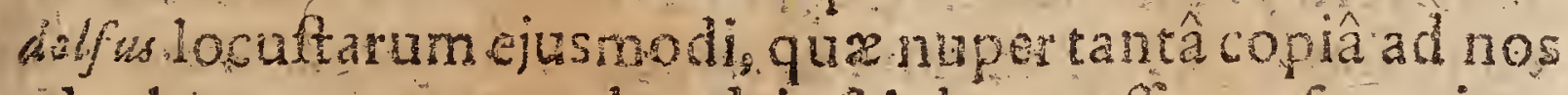
advolarunt, carnem haud influbrem efie cenfet, nixus potinmum auctoritate ac teltmonio R. Ansmia Fezan qui arr. 1683. Erancofunti telatus eft, locuras, queis Mauritanivefcuncup, non necere ullimortalin, licet de jisedant innumeras. Telfbiss equidemobjicit, affectum Hlam vermichlorum ex vietus racione quibusdam Ethio

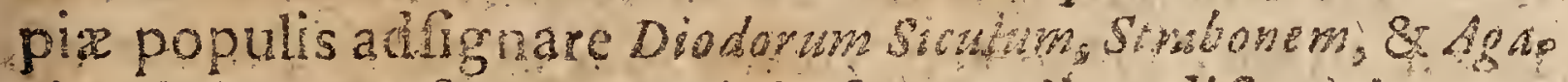
tharbidem. Atnemoes illis foriptorbus difere hoc as. Eeverat. Quppe Diotorus Sistus, pofquam infelicem

$$
\text { C } 2
$$

poptrin

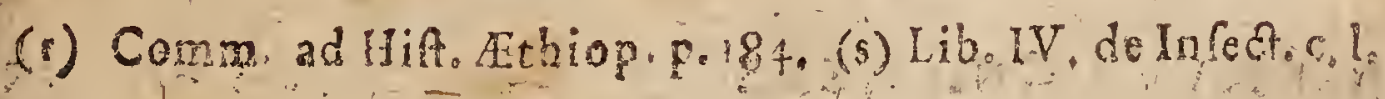




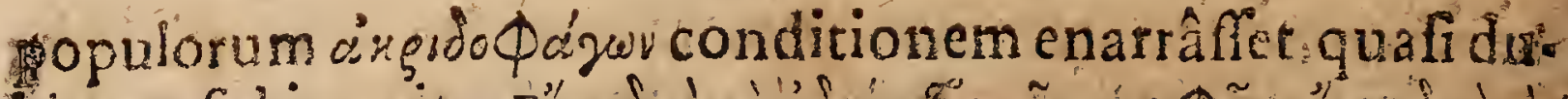

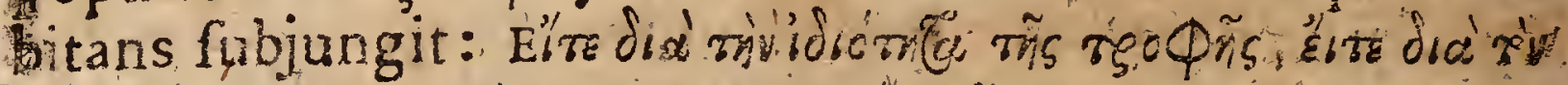

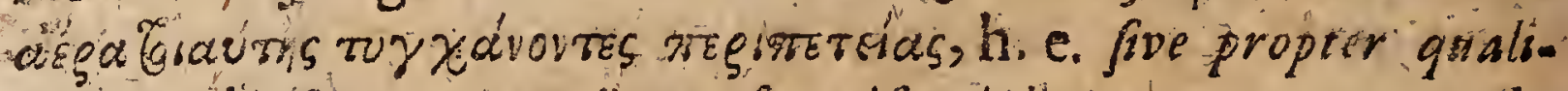
cue cibi, foe prepter aërem fiamiferabili forte utuntur. Strabo pó, cuir de Acridophagis Ethiopibus perhibuiffet, eos

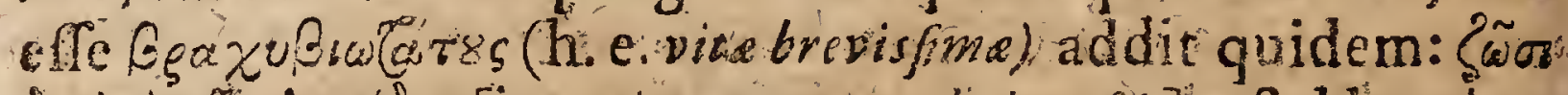

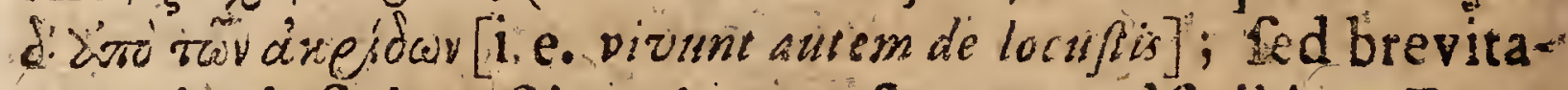
tem vitaipfis locufis, velut cauf $x$, non adfcribit. Et $A$. g bs bides manifelè id in medio relinquit, utrum mifera ilta morsproveniat ex comeftis locuftis, an nativa corpo rum remperie, vel aẹis narurâ. Sic enim fribit : ótb

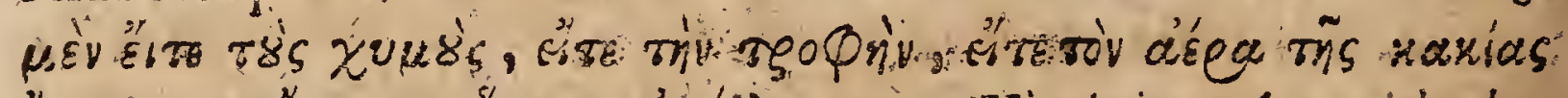

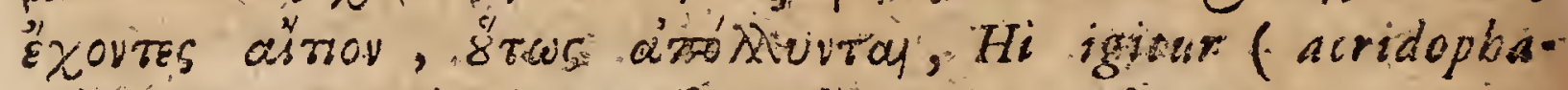
$\left.g_{1}\right)$ fove corporis fuccus, five alimentum, five aër corruptus in calf fit, iftum inmodum intereunt. Eiffe, ex victus ratione dirgrbo $9 a^{\prime} y s$ contrahere corporis intemperiem, inde tamen evinci nequit, quod locufta in fo ac pir. Je infalubres nint, corporis q; corrumpant ter perien, acm ortem accelerent. Pam cibi etiam in fo acoer fe fani ac falubres: fi infum entur \& fallanur, fcorbutum producere poffunt: Jam verò popul a'nerdoфajor tefte plisio ( $t$ ) locuftis vivant fumô \& fale curatis inannua alimenta. Imò fi $\alpha$ Heroóayoilli vefrerentur losuftis recentibus, nec igne fu.: moque duratis, inde tamen, quodnimo acnero earum ufutemperiem corporis everterine, mortemque pramaturam 6 bi accerfiverint, conclídi non poteft, easin fe ac per fe effeinfalubres. Multa enim, qux in fe ac per fe falu. bria funt, immane quantum nocent, nimis ac immode. atèis utare; prour e. $g$ vinum in fe ac per fe falubre eft; eff calorem naturalem extinguat, firmodicè fumatur :" sic \& nobilifima aromata, opium, crocus, \& alia; fi nimium accrebro iis utare, mortem accelerart, \& tamen in feas per:

[0] Lib, Y. H HA G, Nat c, XXX. 
fe falubria funt Objicit Velycbius porro, locuftasederé oleral Galentm autem arbitrari, quod olerum efus fanitati minus: conveniat. Sed nechuic objectioni quicquam ineffe ro. boris, praclarè oftendit Illuftris Ludolfus (u). Neque enim Galemus (x) qvando olera paucifimum dare nutrimentum ait, de infectis \& pecoribus, fed de hominibus differit.Nec verò $a b$ animalium cxteroram cibis, qui homini falubres funt vel infalubres, ad falubritatem vel infalubritate carnis. eorundem rectè concluditur. Certè porcorum, galìnaram , aliarumq; avium quarundam caro im $f$ infalubris haud eft, etiamfi vefcantur reb g, qua homini minimè funt falubres. VI. Non autern falubris tantùm in fe, fed etiam efui grat a, olim hodieque à multis' gentibus locuftarum caro ha: betur, Arifopbanes (y) scribit:

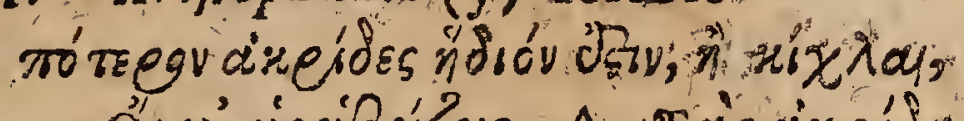

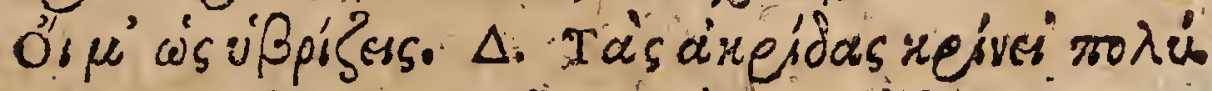

Iltrum locufte fveviores. fint, qudim turdit?

Ebeu!quam injurius es.D. Locuffas judicat multo (fvaviores). Diodorus Siculu. $(z)$ narrat Tocuitarũab Ethiopibus deferta regioni conterminis occifarum magnos coacervari cumu: los, easque falfugine perfperfas \& convenienter macera-

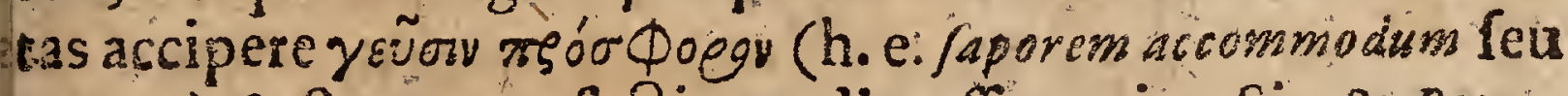
eratum), \& fine putrefactione diu affervario Sic \& Petrus Kirftenius (a) hoc fe ex Arabequodam, quem fecum habuit, audiviffe memorat, quod quibusdam Arabix incolis lo. cuft $x$, fi foli ferventi fuerintexpofitx, \& ab ejus fervore ratis intumuerint, cións foavi/jimus, effe credantur. Cuiconfentit, folepbus de S.Angelo, Tolofanus, (b)omnes \& fingulos in

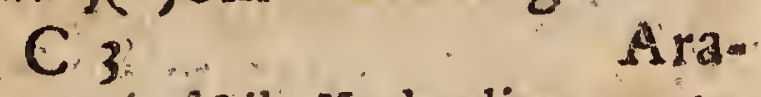

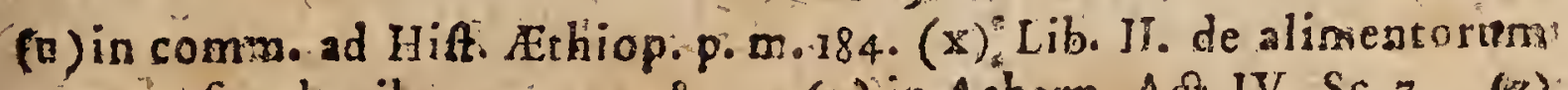
facultatibus cap.40. \& 50. (y) in Acharn. A A . IV. Se.7.

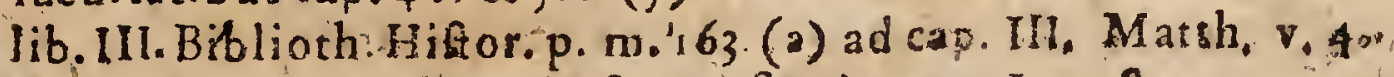
feqgi (b) in Gazophipglacio fue Perfico ia voce Losufta. 
Arabia edere iftas locuftas cun maximo appetitu, enat. rans. Sinenfes (c) delicis aliàs afveti easpro cupedic ha. bent. Mauritanif (d) Africa populus hodieque locuftas, qurejusdem geners ac figur lunt cum noftrtibus, a. viae colledtas coqune 3 efitant, eas mulò duaviores effe pullscolumbarum, ajettes.

VILNec yeritat hujus hiftorix praiudicat quicquam, quod Germani cibmifum naufent \& aver fehtur. Gu. fus enim inter nationes differ, \& ala alis grata, alis in. grata videntur, prout quilibet affetusef. Hinc \& ipfe. roet cum clenardo(e) dixerin: Malo perarem unam, quam locisfas viginstio

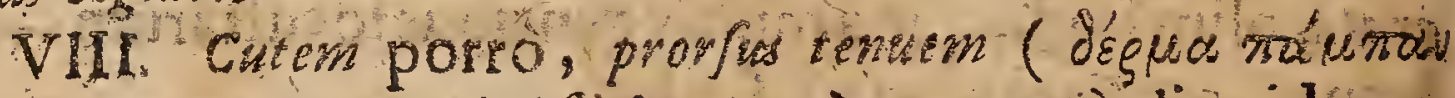
$\lambda \varepsilon \hbar \hat{o}$, ut cum Ariftotele (f) loquar) autcerte aliquid pretenue cuti ává $\lambda$ ono non ad onnes corporispartes, fed ad alvum habent. Quippe coxis dura cruftâ inteetis, intra quas caromollis eft, nec non ad peetus crufâ plurimâ, dorfoque cruftató confant, ut quafiloricata videantur. Mirari igitur fubit, acutifimum aliàs Philo fo phum, fulim Cafaren Saligerum (g) hacce foribere: utinam arifortss

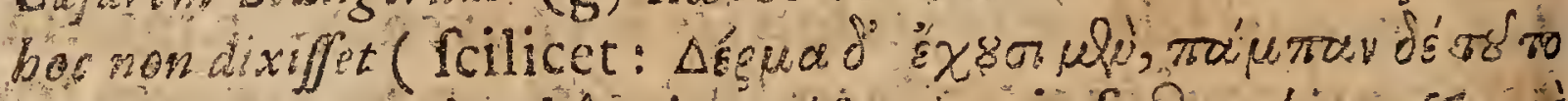

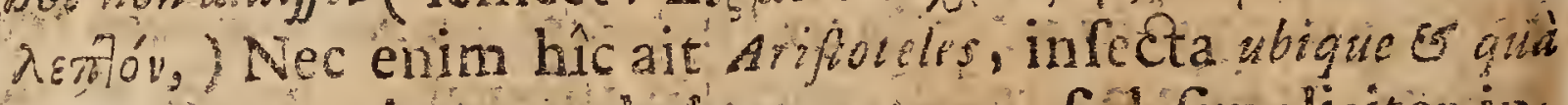
omnes corporis partes habere cutem; fed-fimpliciter inquit: Ac catem quidem, fed pror fus temuem babent. Nam-

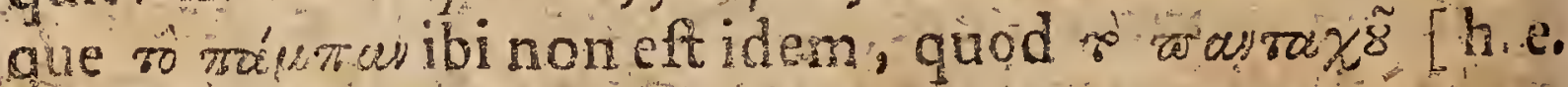

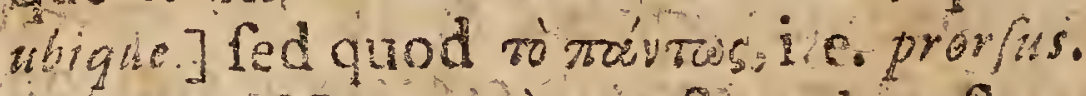

IX. Non crgo conftane locufta corpore incus forisque duro, ut quidam de infectis generatim pronunciant. Neque enim alvus tantum mollior ef, fed \& obfervance, Scaligero (h) intra coxas durâ cruftâ intectas, ac intra dorfum cruftatum caromollis continetur.

(c) Joh, Neuhaf in defcriptione regui Sinarum pag. 377. (i) Ludolfo in comm ad Hit. Ethiop. F. m. 176. 177 . (e) In Epift. L. p.m. 73. (f) Lib. IV.Hit, anim。c. VII. (g) Comm, in Arif. Hiftor. de Animal. Lib. IV. c, VII, (b) ibid. 
* Caput duriori quadam, (eu (utaccuratius loguar) ficton cruta, quagalex formam praber, collumqinvolucrô alquô collarimonachalis peciemgerentecinctumelt. Similes omnino nofrares quoad has partes funtillis, quas in infula Tayowan \& Formos confpicuas ex Hiforia legationis gujusdam Sinenfis Ludolfus (h) fic defribit anno

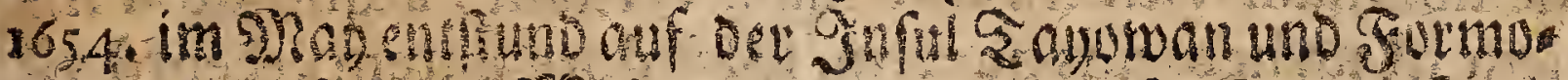

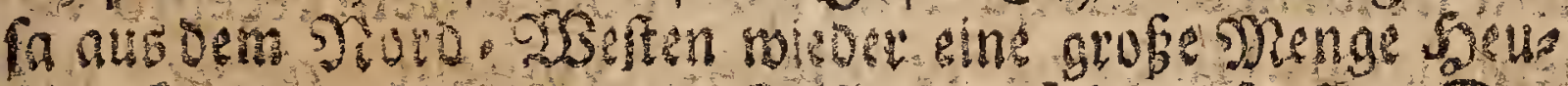

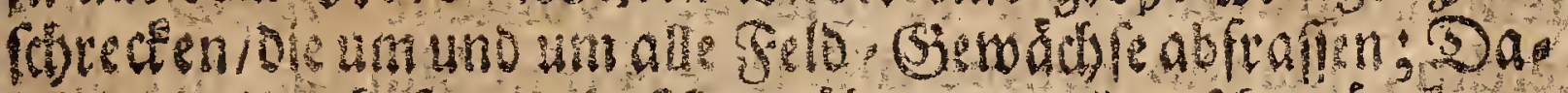

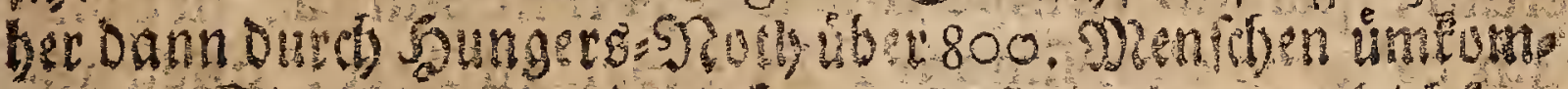

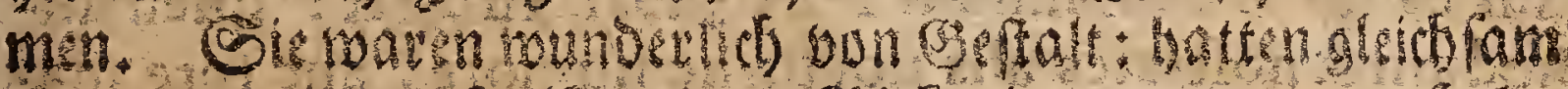

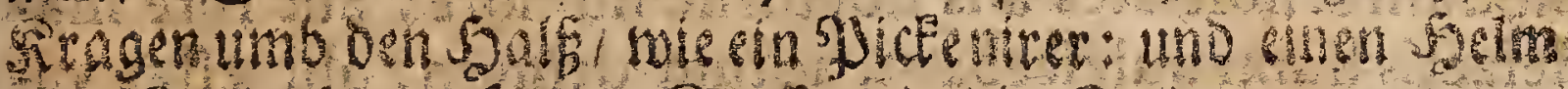

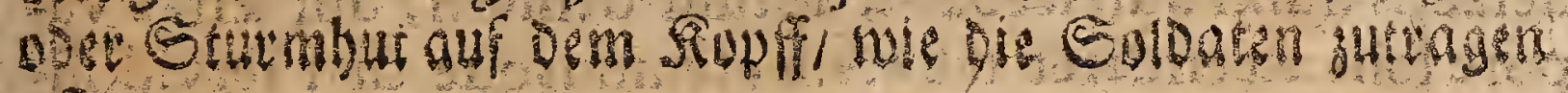
ptegen.

XI. In quibusdam nofratiom ex collo, \& quiden Atimex collarii ifius Monachalis inito crifta quadam ornamentialicujus, tefcio cujus, formam pa fe ferens, $c_{0}$

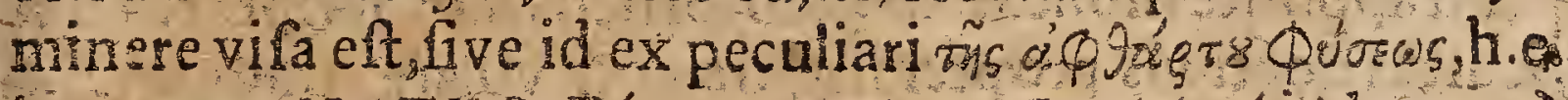
incorrupte $N A T U R$ E (ut cum Sexto Empirico (1) loquar) provifu, ad dehortandos mortalium luxuriantium ani mos, five cafu (ceuloguuntur $P$ byfici) per aliquam à com muni fecundum fpeciem difpofitione degenerationem factum fit.

XL. Licet vilia videaneur efie animalcula, magnum tamen habent os, ac in occipitio, 2 quidem in feapularum commifurâ, dentes duos siguicantes, vididosylatosga ad fruges abfumendas egregiè natos quos inter feterendo (ex fen tentiâ plinic) fridorem edunt. Hinc leonini dentes $A p o c$. IX.8. locufis aligmantur, quando obidemdicitur: odótrs

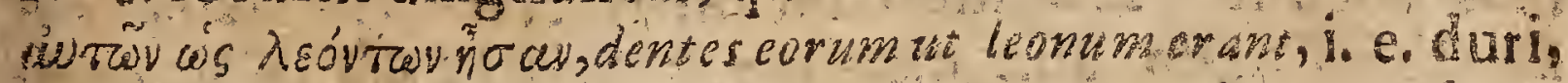
validi, acuri, Atque exdentium illorumiobore ac duritie

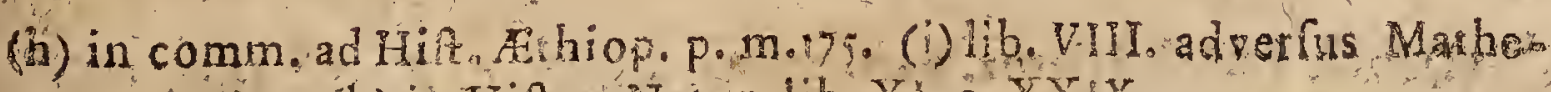

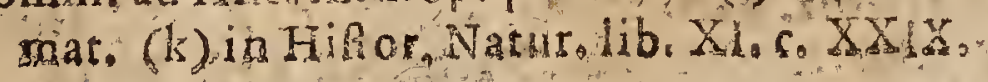


tie fit, ut, ceu Plinius(1)ait, omnia morfu erodant, \& fores quandoque tectorum. Arabes quoque docente Bocharto (m) illud, quod ab ipfis denorfum eft; vocant denticulatum in ferremodum.

XIII. Oculos gerunt patentes ac duriores, ut quafi per membranam vitri translusidam cernant, atque ob duritiem iftam hebetius quidem, fplendore autem receptô vident clarius. Hinc evenire videtur, ut volitent potifsmum in. terdiu, quando nempe difcursâ jam nubium ac nebularum caligine clariffimum folis jubar effulget : quemadmodum \& noftrates alis nodturno humore, aut rore madefactis humi quiefcebant, ac tum demum, ubi æftas vapore folis accenderet tellstem, tempusque diei fervidiff. mum effe inciperet, turmatim provolabant. Et Ligtfootus (n) ex Gemariftis obfervat, coccutire locuftas roris tempore, ita, ut, fi veneris tunctemporis eas, gradum fiftant. Quanquam appofite moneat Plinstos (o) prifcos illos fcriptores, qui locuftas noctibus propter frigora non volare tradidere, $\mathrm{i}$ gnaros fuiffe, longinqua ab is maria tranfiri, fame quoque plurium dierum continuatâ : Et Hieronymus verfum decimum capitis fecundi Joel proprie fic exponat: Premultitu: dine locuftarum obtegentium calum, Sol E LVNA conperieniur in tenebras, S STELLE retrabent lumen fuum, dam lumen in medio nubespofis locuftarum ad terram non finit perdenire.

XIV.Ante oculos pratenduntur noftratibus duo quafi pili, quos Ariftoceles (p) vocat repaías, h. e. cornicula, feu, ut Theodorus Gaza vertit, antennas. Eorum ratione noftrx locuftæ horrereaut horripilare rectè dicuntur, quàndo illos erigunt. Proinde cùm in tractatu Talmudico Cbo. lin locuftarum alix dicantur habere 5TMa (h. e. calpie tium\}, alix non habere, h. e. ex mente Gloffacoris alix glabro,

(1) ibid, (m) in Hieroz. part. pofer. lib. IV.c. V. (n) Hor. Hebraic. in cap. K.Marc. (o) Hiftor. Natur, lib, XI. c. XXXIX. (p) lib.IV. Hifter. Animal, c, VII, 


\section{2.}

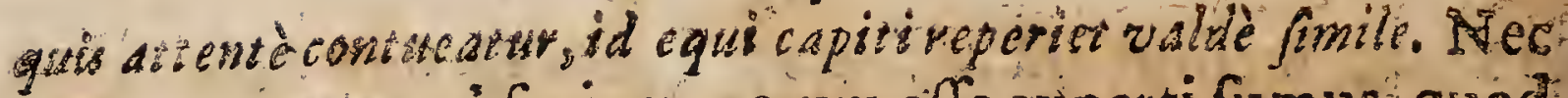
mon, quantum ad faciem, verum effe expertifumus, quod Mubarmiation, Afjarlourienfis Poecta apud Arabes non inceLebris, ex verione Samuelis Socharti (x) fcribit: Habent, (lo

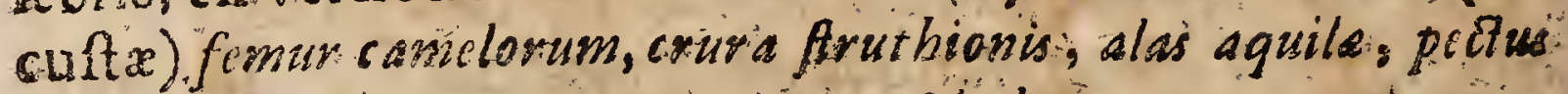
líonis. Caudatis vipenarim terre: O decorant eas equorum. Decies incapite ore Atque ob hanc faciei equina formam Ieali locuftam vocantcavalletce. Hinclicet nonnul: hillud diftum apocal.IX 7 . E fpecies locuftarum fimileserant cquis a billum pararis, ad curfus at volatus velocitatem re. ferant,quâ equis funt propè pares, nos tamen infuper ad taciem equina non abimilem cum Bocbarto (y) attempe. samus.

XVII. Inter caput \& alvum pars quxdam fita eft, qux

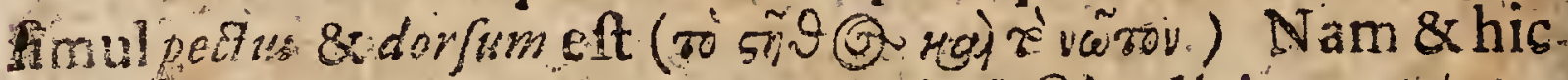
verumeft quod Ariftoteles (z) de infedis dicit: náyray Huy su

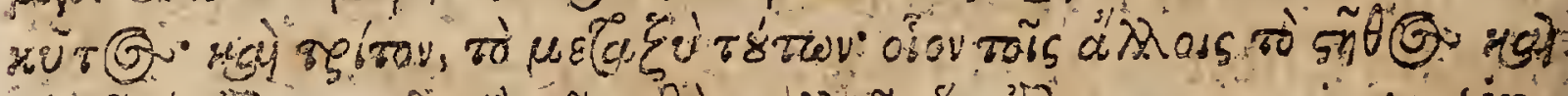

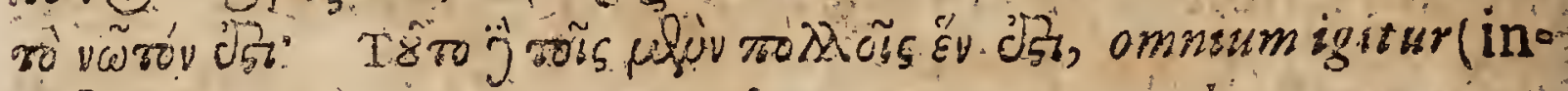
fectorum ) communes partes funt tres, caput, alvus ventrem.

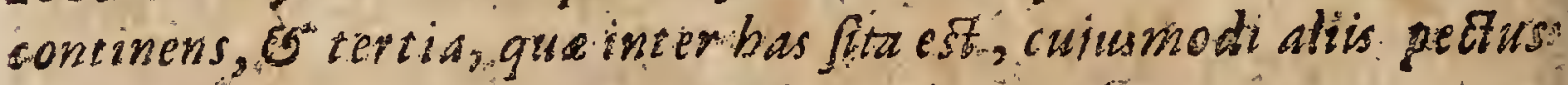
dorfumque dicitur. Hoc in muls is unirum est.

XVIII. Ad peEz pariter ac dosym locuftarum noftrarum crufta plurima ac valde dura eft, ut quafiloricâ indu. tw videantur, Pertinet \& huc, quod Claudianus (a) delo. sulis canit:

\section{- cognatses dorfo dureficiamictus,}

Almavitinatura cutcm.

Atque eò iterum fobanzes (b) allufire videtur, aim de locuftis myticis inquit: Et lonicas babebant tanquan loricas fempas: Et ob hac naturamuninienta noftrates locufta $\cos 0$

(x) in Hieroz. part poler.libr.lV. C. T. (y) ibid (z) Hinot. Anmal. lib. IV.c. VII. (a) in Epigrammatibus Epigramm. VI. griod eftedelocutis. (by Apocalo ax: 8 : 
coco ferri impetu, \& neque homines neque enfestimere videntur.

XIX. Dorfo vents fufor fubicitur, in quo nilef, ni. fintefinum, \& quidem non froplex, fed fexusjum ac replica. tum, quod, utin infectis aliis, aboreftatim incipiens per cotum corpus difenditur. Hocipfum jam olim abrerva-

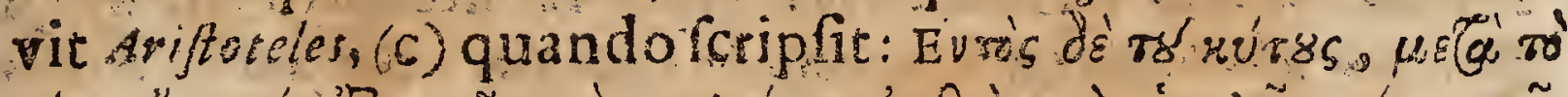

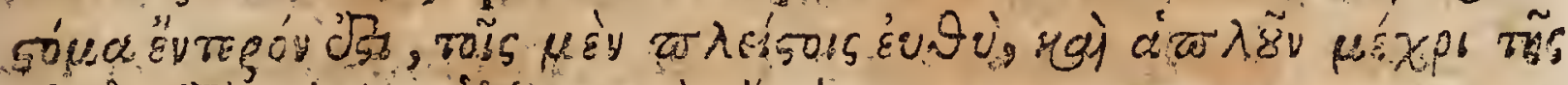

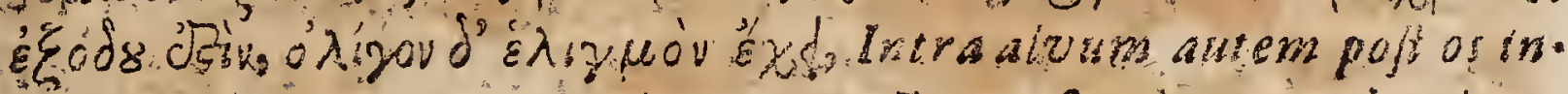
tefinum climaxms particorim retum, fimplexque ad exitum

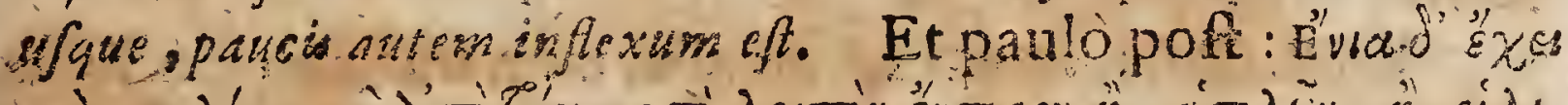

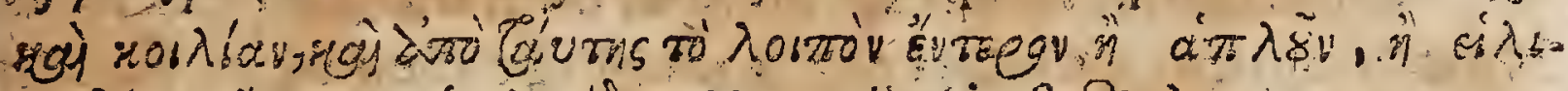
zulúo, cioreg as dingldsc, Nonnulla (infecta) etiam ventrom

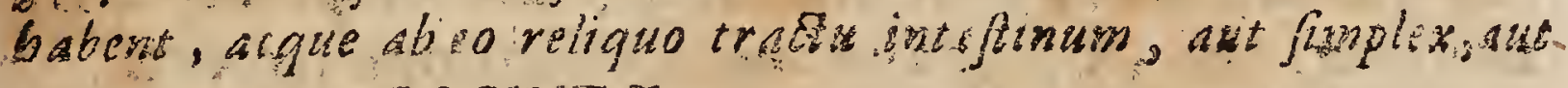
Tolicatum: Ut LOCVSTL.

$X X$. Cumalia quxdam locuftarum generant Thomas Moufitu (d)docet, habeant candam, \& vel exeremâ caudâ vel fupra caudam dos trefve geftent aculeos, noftrates locufxe caudà quidem carent, redin fine alvi quatuor $/ f^{i-}$ ulapanio obtuforahabent. Hinc cum Dodore Tamu dici (e)tradant,gvatuor locuftarum foecies à More enarra.

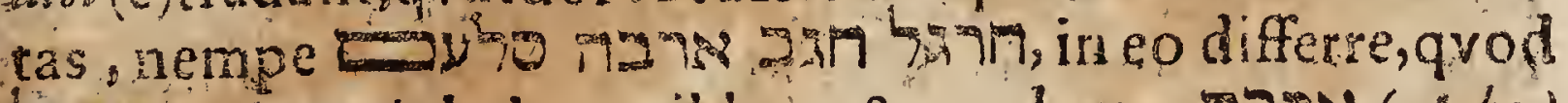
9.97 (cbargol habeatgibbum \& caudam, $727 \%$ ( Arbe) neutrum, $D$ (shom) gibbum, fed non caudam, 2n (cbagab)caudam ine gibbo locufta nofrates,quippe gibbi scaudx expertes ad eam fpeciem, qux dicitur, eruntreferendx.

XXI. Quatuor ale maculofiores, longiores corpore, totumque illud à fuperiori parte contegentes, à collo fubtus criuntur. Unde nofrares is accenfendx funt locu-

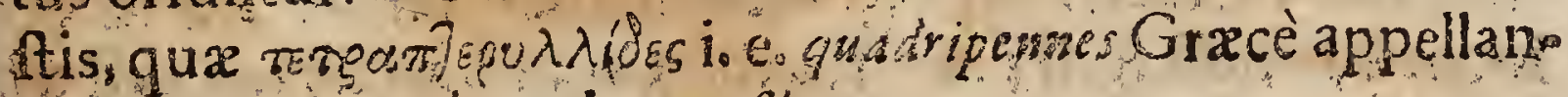
tur. Arifopbacs in Acbatnenfilms.

$$
\text { D } 2, \quad A^{\prime} \lambda \lambda^{\circ}
$$

(c) loc.cit. (d) in Thearro infectorum cap XVT. P. M. II\%० (e) in

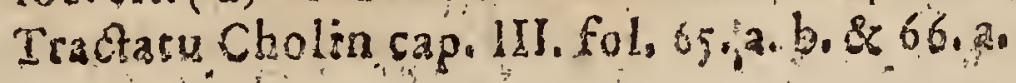




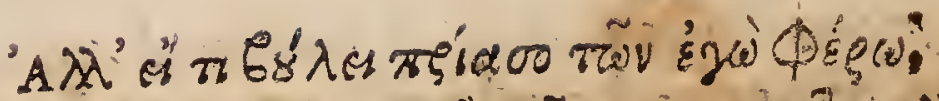

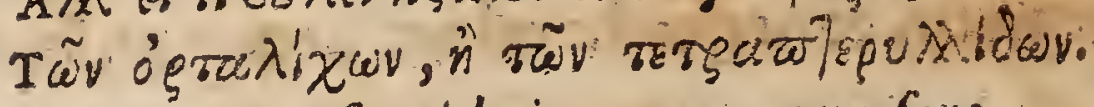

Sed eraito, fi quid vis corum, qua fero,

Gallorum aut quadrionnium [ feu; quatuor alas habentium.].

El ad hanc vocem vetus Scbaliaftes, ac ex co suidas fcribunt:-

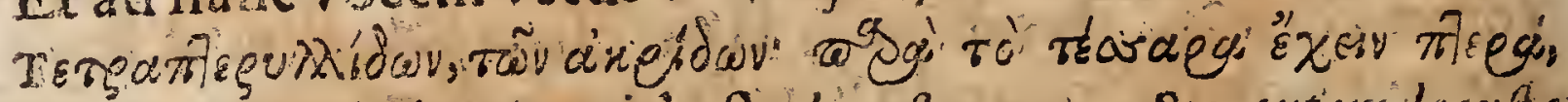
Q2uatuor alashabentiom, id eft; locufarum. Sic autern locufte wocantur, quol quatuor alas babeant. Quanquam duas vo.

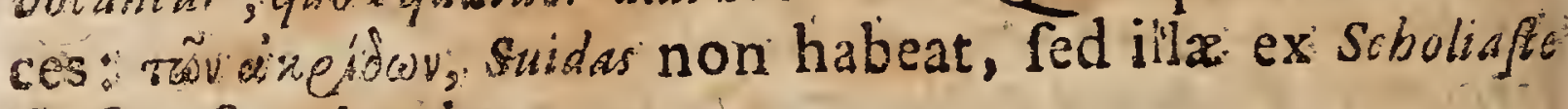
ibifint fupplend $x$

XXI Tot infruet $x$ funt alis, cùm fibi aliquando $\mathrm{ex}$ Numinis julfu in multas regiones longè abeundum fit; hô alarum numerô vincentes múfas \& culices, quibus fuffic vit dix' quialongius a volare neceffum non habent.?

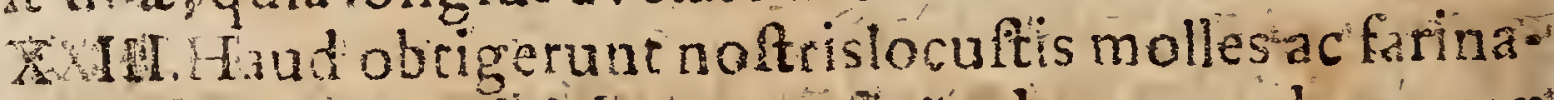
6ras welut papitioni, fed dura quodaño do ac membranace ala: Defticunturtamen noftrates cruftallâ five vaginâa quam Devs locufts aliis quat figuram Atbandfus Kircberut (1) estibst obalarum iftarum fragilitatem impertitus eft, ut filicetin eaalas fuastecondant. Eadem vaginafriforcli(g) dicitur "zurgov: Quzvoxidem notat, quod integumentums

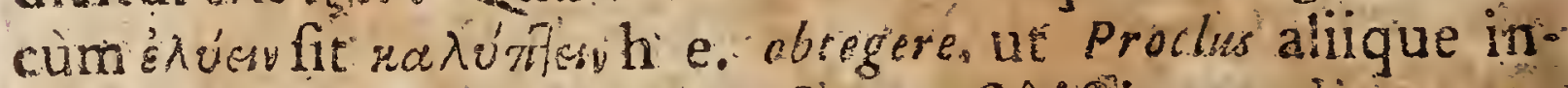
terpretantur: Unde \& locufta cruftaificismodi armatx

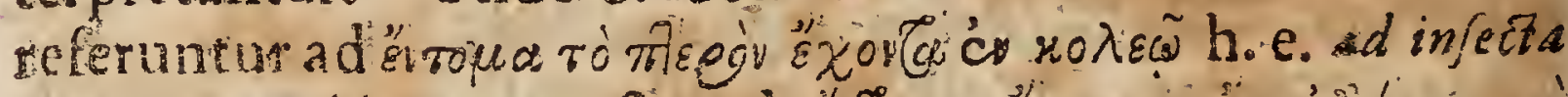

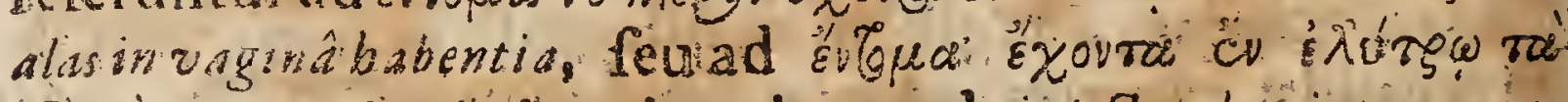

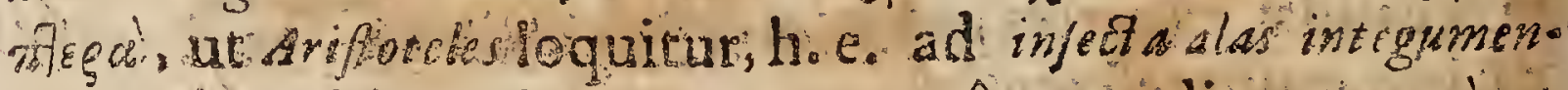
to quodam obautas babmia, gux unâ voce dicuntur rico-

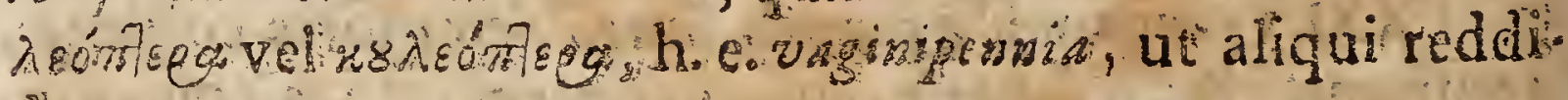
derunt:

XXIV. Cxrerum noftratium locuftarum alx fricte Joguando non funt penna, ut in columbaliisque avibus cuiro

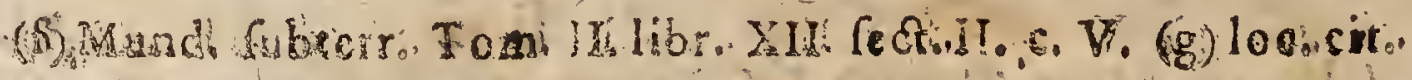




\section{8}

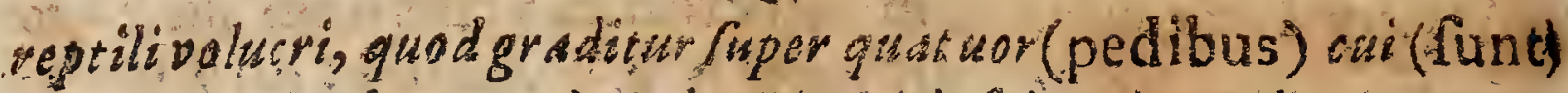
cruratura (vel prater) pedes ejus ad falandum illis in terra. Cui locuftarum defcriptioni Ratim fecialis earum deno. minatio fubjungitur, qvâ alia appellatur arbe, alia sol. amalia cbargol, aliachag ab.

XXVII. Tantum vero pedum numerum eo à natu. ra acceperunt loculta, quod f gide fint nature, atque adeò neceffe fucrit, faciliorem reddi greffum ac motum; id quod fit pedum copiâ. Vid. Arifot.lib. IV. de part. animal.c.VI.

XXIIX. Crura illa \& femina locuftarum, cum inarué rint, ferrarum ufum in India prabere tradic plinius ( 9$). Q u a n$. quam ifte in India locuftx quippe Plinio teftecrnum pe. dum longitudinis, majores longe fintis qua gregatim in noftras oras nuper in volârunt, talem omnino ufum in re domefticâ proftare ineptæ.

XXIX. Poftreni dino locuftarum noftrarum pedes: non ad inceffum, fed ad faltum vel volatum funt comparati. Quippe is extenfis \& inflexis locutex ad falien. dum vel volandum attolluntur; quemadmodum Ari-

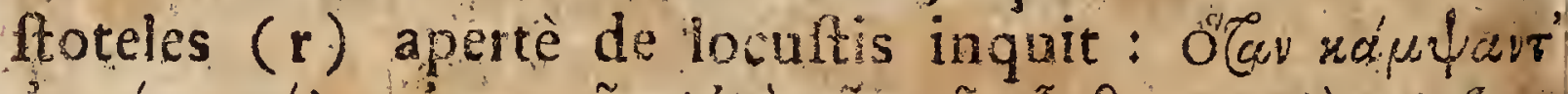

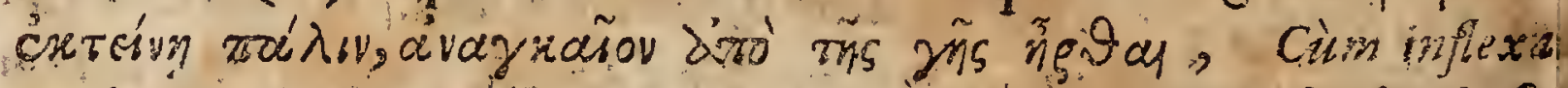
vurfus extendunt ètera attolli vecefje eft. Proinde ipfa Scripura (s) pedes illos novimimos yocat y

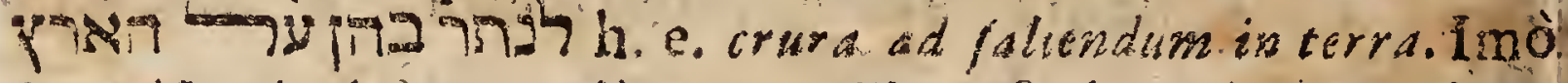

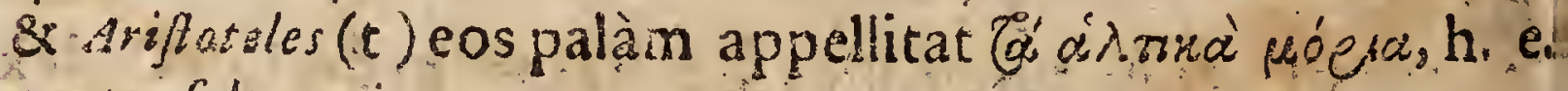
partes faltatorias.

XXX. A tque eam ipfam obcaulam, ut fcilicet eorum innixu locuftx fefe ad faliendum vel ad avolandum è ter. ra elevent pofteriora crura data effe primis ac medis lon giora animadvertit itidem Arifoteles, (u) quando fic fcri bit:

(q)Lib, XI.Hif Nat, c. XXXIX. (n) lih, IV. de parto animal, c, VIo (s) Levit, X, 2I, (u) libr, IV. HiR, animal, c. IX. 


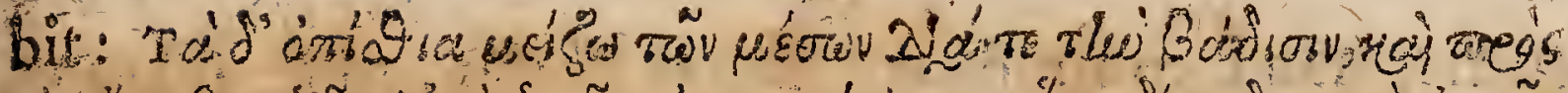

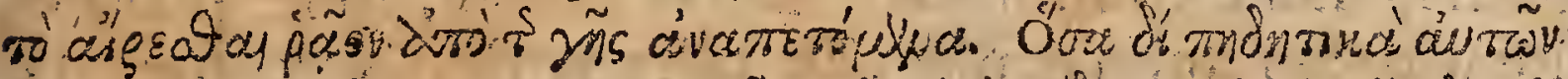
टँच,

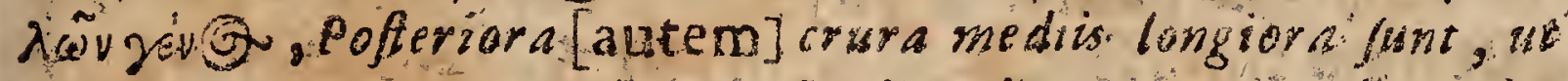
ambulent melius, $c$ actollantur facilius de terra, guando avolar liber." Quod planius ea offerdunt, gua jaliunt: ut lorufae at crilices.

XXXI. Eofdempedes novifimos Arifoteles (x) vocat $\pi \delta^{\prime} a^{\prime} \lambda a_{*}$. Quod vocabulum Theodorus Gaza per gu. bernacula, fulius cafar Staliger (y) per faltacula reddit Illa verfio eâ potintimum ratione nititur, quòd móa $\lambda$ iov \& apud profanos auctores, $(z)$ \& in facro codice (a) guber naculum denotet, atque ut navigi motus gubemaculô. \& quidem olim, docente eleganter scheffro (b), fepe du. plici, dirigitur, ita infectorum motus feu faltus duobus il. is poftemis pedibus gubernetur. Hac autem scaliger interpretatio co refpicit inprimis, quod ro nnda fit faline, Jaliare, atque infecta poftremorum pedum inflexu fe ad faliendum librent. Verum enim vero verfio illa, qvam attulit Gaza, velut Arifotelis menti conformior praferenda eft ac perperam à Scaligerocarpitur Arfloteles (c)enim,

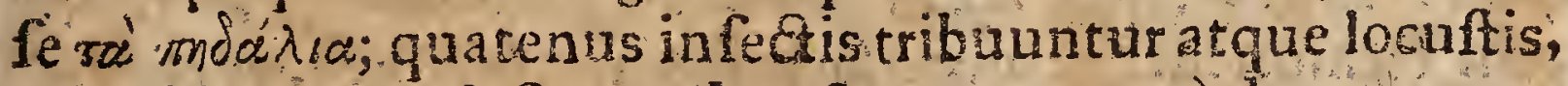
ad gubernacula defignanda ufurpare, apertè docet,quan

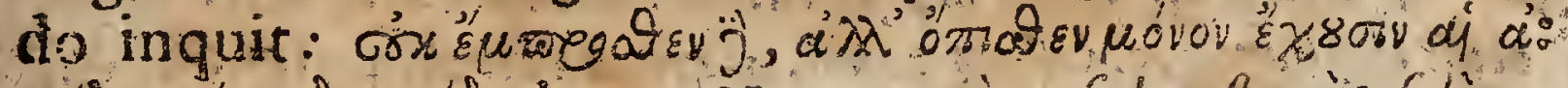

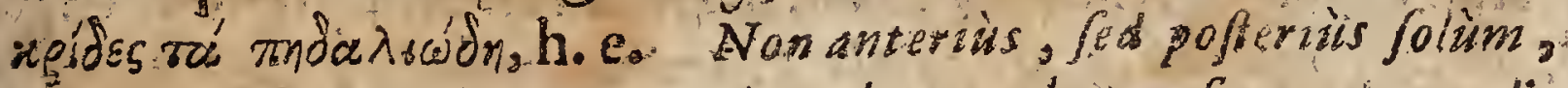
LOG UISTR habent parres in gubernaculorum formain condia tas. Quippe đa moa $\lambda$ cédn dicuntur ea qux gubernaculo. num formam imitancur

XXXII, Dacztero ex is, qua edifferuimus hucus qre,manifentum evadit nobis, qui fenos pedés attribuim us locu.

(x) libr. IV.Uif Animal.c.VII.\&IX. (y) in Commeorar.ad Hi or Anirnal lib. IV. e. VI (z) (z)lian. libr IX.Varior.cap.XL.\& Zueliodor. libr. V. Ethiopic. (a) A cor XXVIl, 40. (b) in librô grudisô de militiâ navali, (c) libr. WV, de part.animal,c.VI. 
locultis, haud contradicere facras literas, qua quatuor faltem pedes animalculis iftis adfignant. Namin reipla facta Scriptura pariter \& Phyficorum fcholx fex tantùm locuftarum cruraftatuunt, ac in ufu falem vocabuli pedis difcrepare videntur, cù $n$ ob fervante $A$ ug faica duo pofteriora crura, quippe non ad incefrum, fed ad faltum comparata, inter pedes haud camputet, Arifo. teles (e)autem, fe in fex illis pedibus as etiam partesiqua. rum enixu locuftx faliunt, connumerare manifefte in.

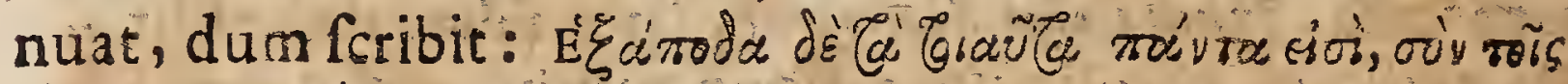

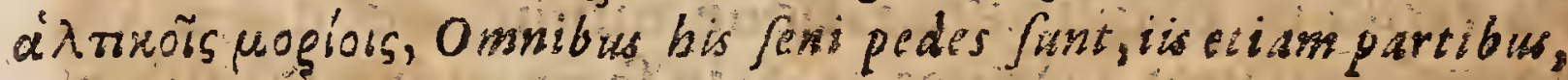
quarum enixu foliunt, connumerstis.

XXXII. Liquet infuper ex partibus locuftarum huc usque explicatis, noftrates habuife locuftarum mundarum quatuor notas à bodzoribus Talmudicis $[\mathrm{f}]$ adfignatas, velut " ארבע 1217 תN $\square 17$ h. e. quaiuor pedgs, quatuor alas, crura longiora, G quodaletegunt totum corpus.

XXXIV. Totum hoc de locufarum naturâ partibus. que caput claudimus verbis Arabis sujusdam Anonymi apud Damirem, qux apud Samuel. Bochartum [g] in Latinum fermonem fic converfa legimus: In locufa quamlibet infirma, natura ef decen magnorum animalium: l. facies equi, 2. ocute elepbont is, 3 collan tauri, 4.cernua cervi, s.pectus leonis, 6. venter forpionis, 7 ale a guile, s. femor cameli, 9 . Arubionis pedes, 10.cauda ferpentis. Namque \& hac omnia, fi folam ferpentis caudam demas, locuftis noftratibus per analo. giam quandam accommodari poffe, ex hactenus dictis liquido conftat.

(d) Libr. II. Retractationum cap. XV.(c) lib. IV. De Part. Arimal. c. VI. (f) in Tractatu Cholin cap.3.fol.65. \& 66, $(\mathrm{g})$ in Hierozoic. Yart, port. Lib:VI, $c, V$.

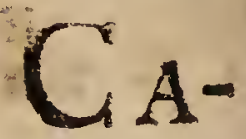




\section{0}

faltantes ut locufta. Certè avicularum expeditis alis pro volantium celeritatem noftrates aquant, \& paucarum horarum fpatio aliquot milliaria Germanica trajiciunt. Sic \& jain olim rarravit plinius (1) à locultis etian long maria tranfiri, continuataplurium dierum (quod maximè mires -mur) fame quoque quam propter externa pabula petunt. Ac ann.1536. exteris trans Pontum Euxinum in Podoliam transmifere $(\mathrm{m})$.

11. Noftratiun locuftarum ordemem in volatu $\&$ in inceffu fervatum quod attinet, illum non collocamus in co, quod, tanquam apes, regem habeant, tacitô quafi con-

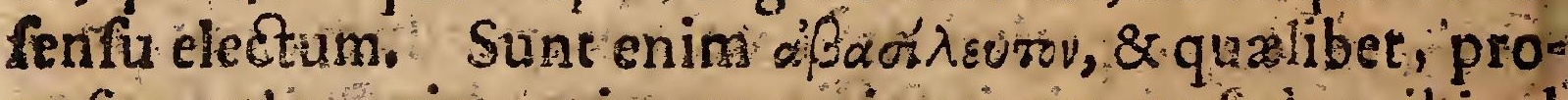
ut fors tulit, prima migrat, aut in agrum, ut fedem ibi ad tempus figat, defcendit. Finc \& Salomon (n) inquit. Lo

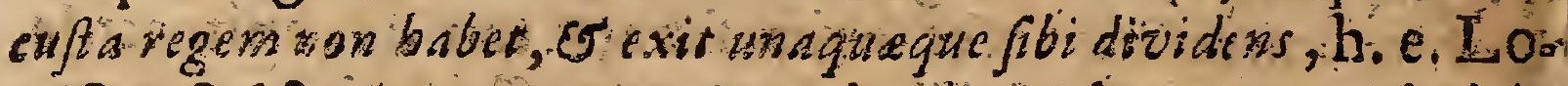

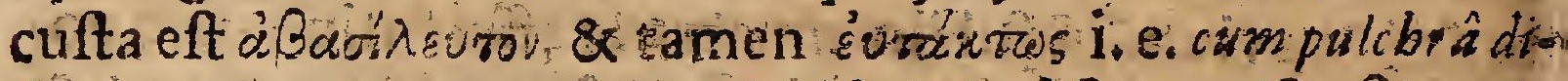
Bofrione (cetinter pretes Graciaddunt) ad fegetes!fuctusque tollendos, velut ad bellum, egreditur, ac fine ulla conteno tonepradarn dividic:

IV. Eô autem ordine locufte noftra provolarunt, ô caftra velut hum metata fuist, ut nilicarem quaf difci. plinam in agmine iprarum cerneremus. Nam noftrates quoque meabant goo indov (hi erdike) atque volabant $\omega$ co (a) (h, e. quafperacies), minimeque fejundx, velut fo

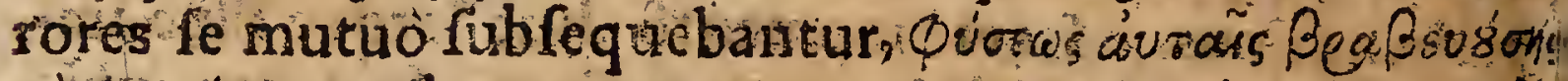

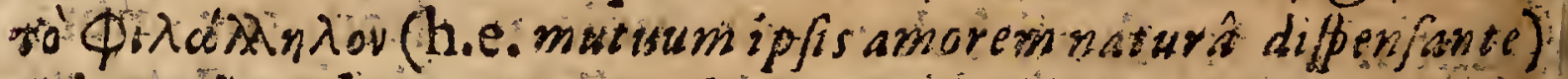
ati Cyritus ad cap. II. goët. fribit. Holtium infar confcen debant 8 per vias incedebant, nulla vifedivelli fuentes! fed tanquam mutuâ confpiratione imperum facientes quemadmodundelocuftis generatim Thcodorstù ad cap I. Fölspronuncrat. Tantô ordine ex jubentis Dei difpo

fition:

(1) Hiftor. Natur. lib, XI d. XXIX, (m) H.og.de Orig \& progr. ido

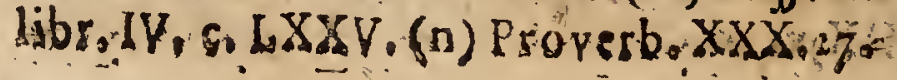


fitione volitabant ut infar teferularun, $q u g$ in pave mentis artificis finguntur manu, \& ne puncto quidem, ut ita dicam, ungueve transverfó declinarent ad al. teram: ceu Hieronymus de locuftis à fe in Palaftina vifis ad cap. 11. 90\% tefatur. Antequam cotum yaftum agmen advolaret, quedam turma pramitebantur, qua velut caftra metarentur. Id quod \& sigismundus von Sircen $(0)$ de ingenti illâ locuftarum multitudine, qua an. 335 . Poloniam, Bohemiangue \& Auftriam vaftavit

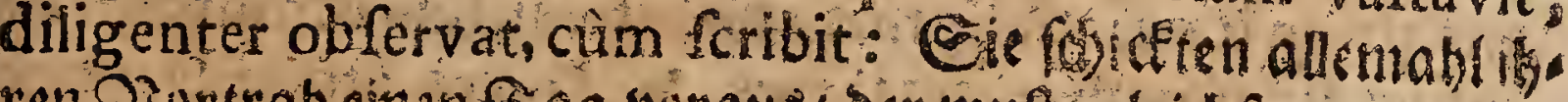
ren 3 ortrab emens ag voraus / oer mufte gletofort oor bas

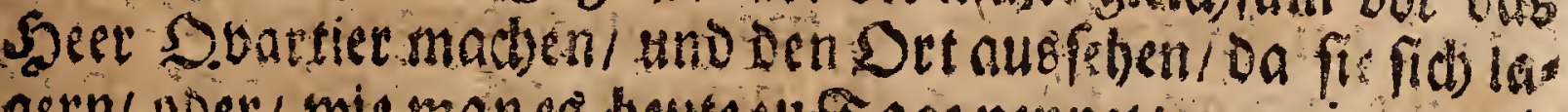
gern/ ooer/ wie manes beute zu Sage nennet/ campien wor

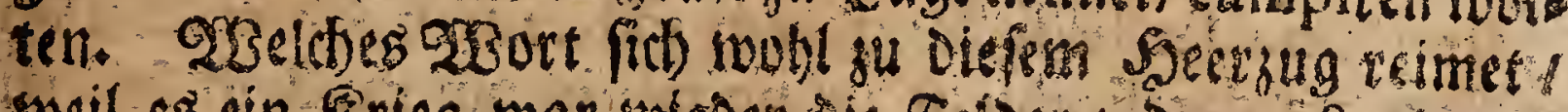

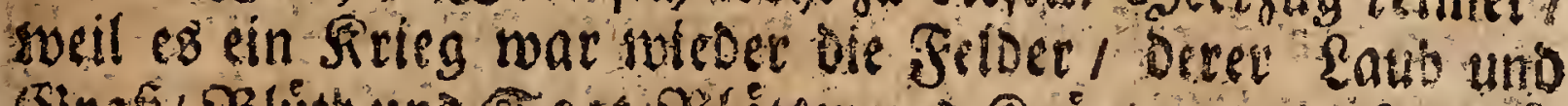

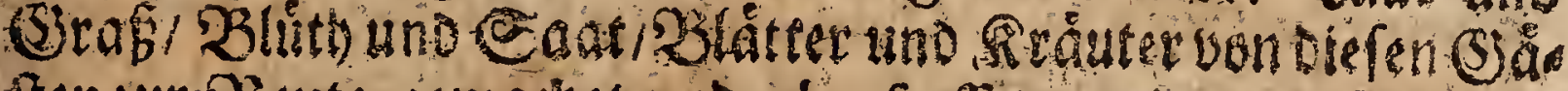

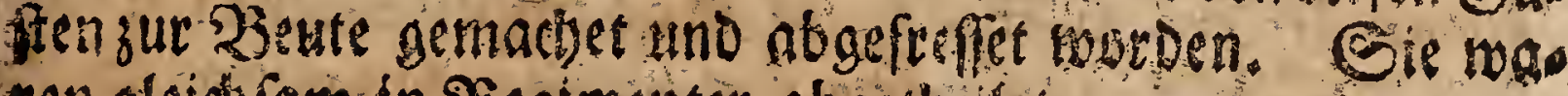
ren gleidram in siegimenter abgetleriler.

V. Didicimus infuper ex locufarum noftrarum no: tu, \& quòd yoga nimis \& inglabilia fint agmina, \& quòd plerumque tum demum, quando fol ortus eft, diesqua incaluit, rore velut excufsô \& à torpore foluta alio fe vo landô corripiant, Subiit hic ftatim animum Propheta Nabum ( p) utrumque hoc jam olim in locuftis expendens. Ita enim dicit urbi Ninive: aggravare (multiplica te) we brucbus: aggravare ut locufta. Muliplicafti negotiatores tuos

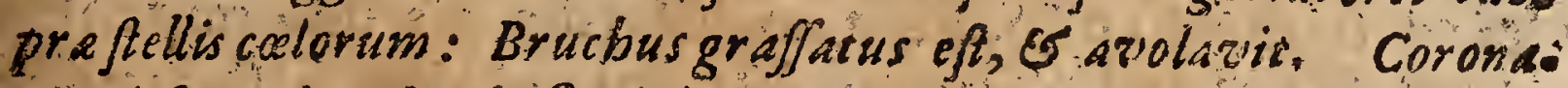
tituifacut locufie ( funt) \& prisnsipes rui us locufa lo. cufarum caftra metantium is fepibus in die frigoris: Solortus eft, os avolaverunt, is non eft cognitus locus edrum, ubi fuerint. Quorum verborum fenfus genuinus parrim ex Cappar. Sanctii (q), partim ex samuslis Bocharit ( $\mathrm{r}$ E 2

inter.

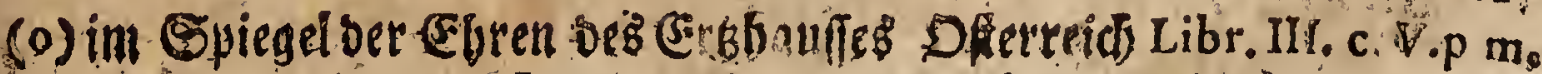
315. (p) cap. II\%, 16. I\%. (q) comm, ad cap, II. Joel, (r) in Hice zozoic part,ponter. libr.iv.cils 
Enterpretationehuc redit: Iu quidem es urbs popu. , lofina, \& incolarum uorum multitudo videtur aquare - Gruchorum \& locultarum agmina, qux nubium inftar operiunt teram \& obumbrant $\mathrm{Et}$ in $\mathrm{T}$. , nibus turplures negotiatores a fylum quarunt, quàm in colis fella numerantur Sed non eft quod confidus tantis copiis, totque mercatorurn oprbus. Uti , nim bruchi \&locufta, qua in arbuftis ac fepibus noctur, nô ac frigido tempore confederunt, fole exorto avolant, , heque in loco, abi priss confiterane, in meniuntur am"plus, fic populi, mercatores, \& Duces atque Princines stui, qui diu inrra monia tua, cum pacata effent \& fecun. , da tempora, fefe continuerunt, ad primimarmorum? ,flrepitum feulicui clangorem exterrit, unanim conferigrate ita derelinquent ut ne mininum guidem fuperfie illorum veftiginm. Alludic gaoque ad ragum hoc as fos aum incertarm animal oavid (r) de feipfo dicens: " 9935

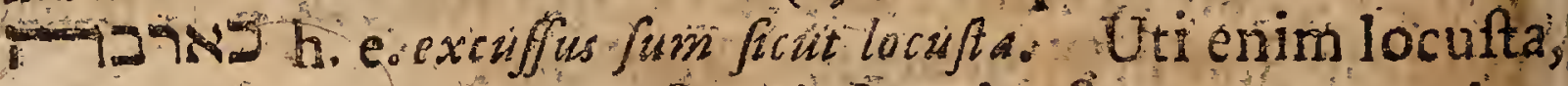
cum nido care vaga elt, \& e fepe in fepem fransvolat ita David qui (ut Abenefras kimibius putant) has fribebat Salem fugiens fine foco \& lare huc illuc difurebat.

VI. Quod locum, quem pervagantur locufta \& unde adventant, attingt, olla quidem peftis dira apud nos rara valdeginfolita eft hominum quippe menoria a pud nos nunquam wifa, fed, ut Ludolfas (s) inquie, epidemia autralin regionan plaga elt jobmes Leo afrisans (i) \$ 01 . Dappers (a) narrant, locuftarum olerumgue tantam confpici in africa frequentiam, ut volantes inftar nebult at alicajus eclipfeos radios folis per aliquot milharia o. Seriant. Scribit \& ille Jobannes teo $[\mathrm{x}]$, re ad antiquifi. mamAfricx civitatem, Tagteffm, magnam locuftarum foli Guperficiem plane contegentium coptam invenife. Arino urrbis

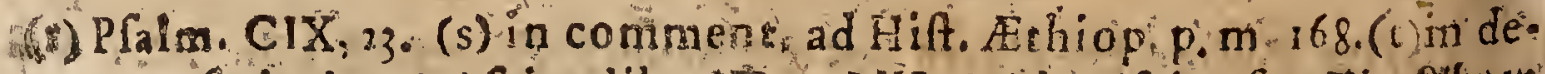
friptione Africelibr, IX. c.LXI. (u) in Africa fua Tis Mogen

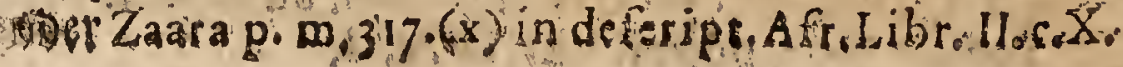


urbis $62 \%$ tanta locuftarum multitudo Africam, inprim Numidiam, invafit, ut ex ipfarum necatarum ftrage orilretur peftilentia, qua octingenta millia hominum confut mebat (y). Sic \& locuftas Tellezius $[z]$ vocat He thiopiaz (qux Africx pars eft) plagam valde communem. EO Africis \& Zephyris ingravefcentibus infinitam locuftarum co. piam è deferto veristempore compelli, Strabo [a]\& Diodorns Siculus [b] commemorant. Cumprimis refert Diodoris, cuidam genti Hethopica ex animalculis iftis copiofum. per totum vita tempus alimentum effe. $\mathrm{Ex}$ recentionibus rerum Ethiopicarum foriptoribus Francifsus Alvarezius (c)

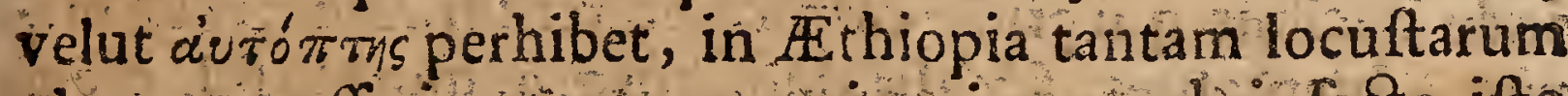
plagam graffari, ut eorum, gui regionem ab infecto ifto infeftatam deferunt, gregibus yia opplete fint pafim, ac ubivis ingens clamor barbarố ululatu planctuque permixtus exaudiatur. In Africam ex Arabia felice per deferta Libyca Numidix \& per Barbariam immenfa illa locuftarum examina pervehuntur (d). Toéorbispartibus vagatur id malum: $p$ arthis \& infectumiftud in cibo gratum eft; ac non raro in Lemno acchreváca gegióne vagatur (e). In interiorem Perfiam denfifim vere folem obumbrant, à deferto Arabix procul tranfeune (f).Ex Africa autem Italiasin maximè infeftare, fxpè po. pulo ad Sibyllina coacto remedia confugere, teftiseft plinig

(g). Et ann, 59 , ex Africd transvolarant in Long obardiam, regnante. A gilutfo in ea.Sic\& Georg.Agricola (v) fribit, locü-

(y) Vid. Epitom. Liviana lib. LX. Orofius lib. V. e. XVI Paulus.Dia.

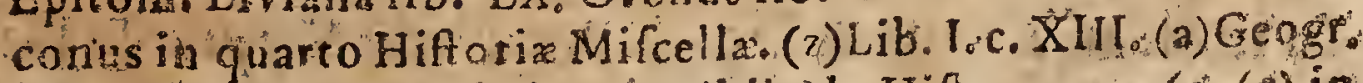

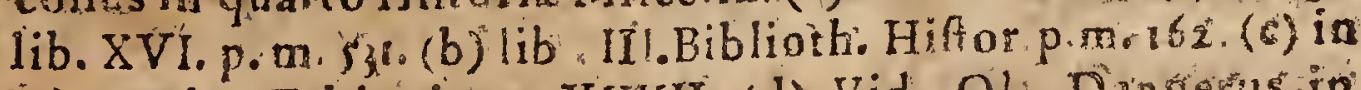
Itineratio Ethiopicoc XXXIY. (d) Vid. Olo Dipperus in Africa fua tit. Libyenober Zaara po mi 317 . (e) Vid. Pliniwst. XI. Hiflor. Nat. c. XXYX. (f) Jofe phus de S. Angelo. Tolofantis, in Gazophylacio Perfico in voce Locufta. (g) lib.XI. Hiftor. Nato c. XXIX. (h) Vid. Voff de or. \& progr.Idolilibr.IV'c.XV.(i) in libro de animantibus fubterrancis, quem ad Georgium Fabrifo

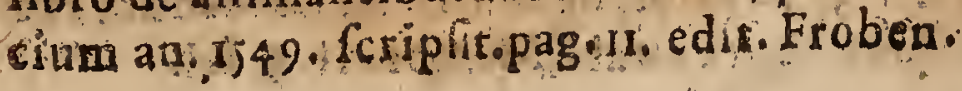




\section{6.}

Atas, diras herbarum, leguminum, fegetum, firpium pe: Ates, ann.If42, ex Africa, ut grondam et am fopè in alias Eu. ropa oras, in Pannonias, in Daciam, in veterem regionem Marcomannorum L ygiorumque gregatim in volaffe. Multò antè, anno videlicet urbis 581. C. Popilio Lanate, \& P. Elio L igure COSS. locuftarum tantx nubes à mari ven: co repente in A puliam illate funt ut examinibus fuis agros late operigent (k) Sigeberto tefte an. 874 . poft Chriftum natum in $\mathrm{Galliam}$, difciplinam yelut militarem inter fe fer. vantes, horrendam vaftitatem invexerunt, praminis fub. inde ducibus, qui pridie caftra metarentur. An.1335.ab oriente adventantes, fex alis dentibusq; gemmarú fulgorem evibrantibus praditx, Poloniam, Bohemiam, Auftiam \& alias Germania provincias immane quantum devaftarunt (1) Superiorisfeculi ann 4 r incredibilem multitu. dinem ingentium locuitarum primum in Fallackia exor tam in circuitu cuncta $L$ eopolim usque milliaribus circifer fexaginta, ad folum usque devorâfe, Laurentius sus rius (m) teftatur. Anno is $4^{2}$ tanta earum copia Italiam 2. Germanian [n] pervafit, utin Alarcbia [o] ad equi ungulam usque jaserent, earumque volatus in Italia [p] per fex integras horas perduraret. Eodem ferè tempore ejusmodi tempeftatem in Mcootide atque 1 quilonibus ortam, \& in pannonias delatam obruife cunctam regionem, Acribit Jolius Ge/ar Scaliger(q). Quantum agrisi Romanis damnum annô labentis feculi quinquagefimô fextô dirum ifthoc malum dederit, Athanafiu Kircherus loco fuprà cita. cô indicat, Tandem Dn-D. Foacbimus.Hoppius [r] fe Franco:

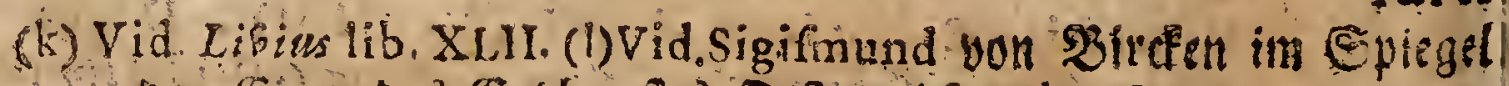

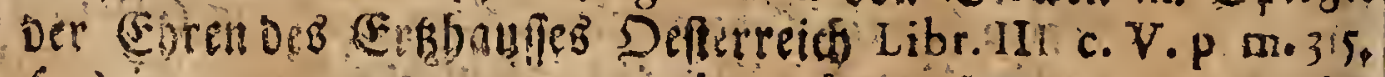
(m) in cornmentar, serum in orbe geftarum p. $m .46 \%$ (a) Sleidan. lib. XIV. (o) Vid. Franzius in Hiror. Animal.p.m. (p) Vid. Menocbiusde Remed.recuper. polfefs? Rem. 12, n. 3 (3) libr, de fubril. ad Cardatum exercis, CXCIT. (r) in dif̧ute, Lu prà cisatâ, Membr. Il. șo II! 
furt ad Viadrum oblervaffe inquit, quod ann. 168r.in Marchia locuftx tantâ multitudine in altum fe contu. lerint, ut Solis quoque fplendorem fuâdenfitate excluderent. Proinde Sialiger reetè caftigae Cardanam, qui afri camperè folam locultis abundare dixerat.

VII. Innumerabilem illam locuftarm copiam tunc, quando exuno locoin alium travolat, infignem fonum Atrepitumque concitare, \& animadvertimus ipfimet non ita pridem, \& dudum ab alis obferva? tum fuit. Norunt traetuum noftrorum accolx, infeEtum iftud, cùm nuper è terra fe attolleret, ac in fublimem fe elevaret ära, pracipitis aqua ad afperos lapides allifa ac per faxa decurrentes, aut venti arbores quatientis fo. num reddidiffe.Confimilem ftrepitum in infula Tagowan \& Formofa ejusmodi locuftarum rubem concitaffe, Ludolfus (s) ex. Hiftoria fecund legationis Sinenfis fic annotat:

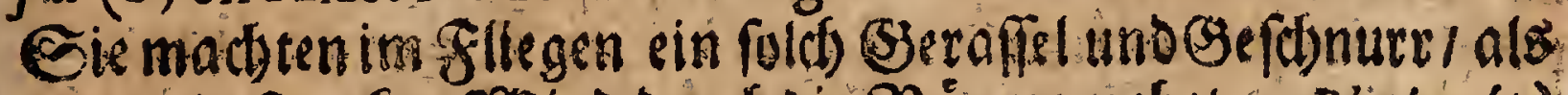
wonnein ftarce oşino ourch cie Báume gefiet. Plinius $(t)$ jam olim ait, locuftas tantô volare pennarum fridore ut alix alites credantur. Cyrillu (u) item ex relatione aliorum contendit, eas non tantùn in agros decidere. cum Atrepitu, fed etiam, dum proftratas fruges manden. do comminuunt, dentibus edere tenuem quendan fonum

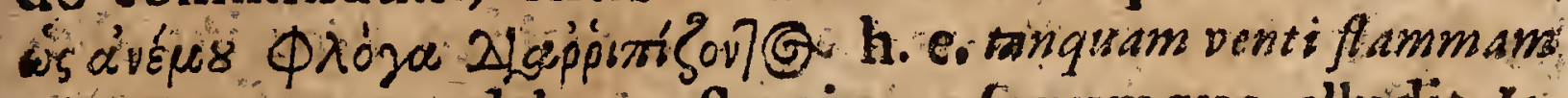
agrantis. Atque ad hunc Arepieum fonumque alludie 10 . bannes $(x)$ de locuftis myticis fic foribens: Soniu alarwm iis ut fonit tes curruim, equis mults ad bellsm currentibis.

VIII. Notat quoque Plimims (y) locuftas circa duo noaximè $x$ quinoctia terendô inter fe dentes firidorem edere. Vox locufaram, inquit, proficifi ab occipitio videtur Eó locô in commiljura fe apularum babere quafj dentes exiftiman.

Sitro

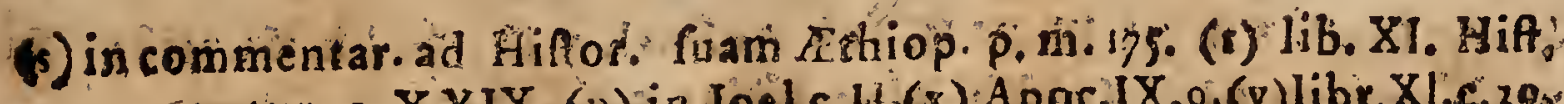

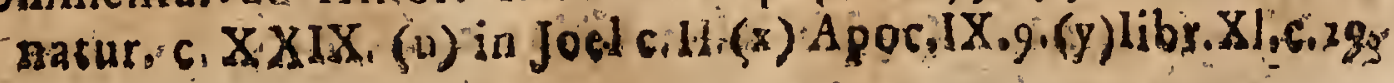


Ger cosque inter fe terendo fridorem edere, circa duo equinodti maxime, ficut cicadecirca folftitium.

IX. Neutiquam verò in locuftarum noftrarum fo. no elegans ac muficum quiddam potuit deprehendi, quod de iftiufmodi animalculis-Tbeocricus (z) fe ipfum, tanquam impar ad certamen cum Poeta magni nominis, extenuans, \& Scboliafes Grucus aliàs pradicant.Pofquam enim Tbeocritus dixiflet:

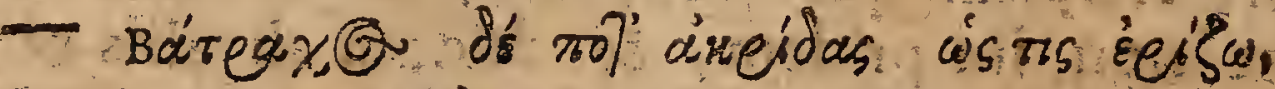

sed velut rana quadam cont i locuftam contendo;

scboliaftes Grecus hac annocat: Tũv dréidov ció lives,

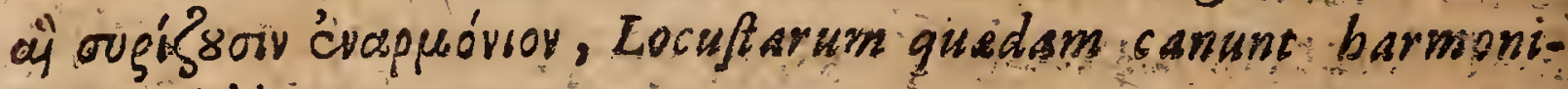
cum quiddarm.

X. Unde autem oriatur fonus ille ftrepitusque, difquir folet inter Pbilofopbos. Putat Ariftoreles (a) proficifi eum ab exterioris corporis motu, nempe à cruribus novifimis motis, iisque attritis, \& affricatis. Ai $\delta$ árés $\delta s$, inquit,

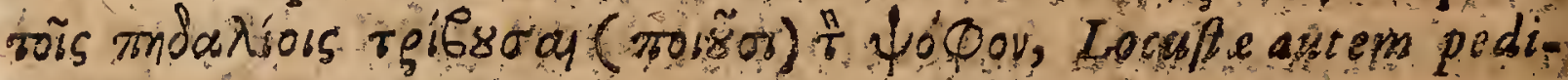
bus fuis poftrensis affricatis fonant Cujus fententix mentionem facit Plinos (b) ita fcribens Locufas pennarum c feminum attritu fonare, creditur fane. Imo ip fa fa. cralle e fonum ilfum attritis alis adfribunt, quando de locuftis myfticis dicunt : Sonitus ALARUM is ut currum. Sed $\&$ plonits (c) alio in 100 fuperius alle. gato freptum ithan dentibus jnter fe contritis mani. feftè tribuit.

XI. Aft fententix iftx conciliari vel nullô nego. tiô queunt. Videlicet locuftarum examina fedentia. humiac conquiefcentia terendô dentes, in volatuautem ferinum alarum que contritu fonum reddunt.

XII.

(a)IdyH.VII (a) lib.IV.Hif or Animal, c. IX. (b) lib.XI. Hifor.Ang. c, LI, [e] lib,XI,Hif, Nar, c XX)X. 
XVI. Nimirum locufte vel recens prognatx funt; weladultz. Recens natz funt admodum parvx, nigrantes, \& fine cruribus pennisque reptantes: ut eft apud Plinium $(\mathrm{g})$, acin noftris oris videndum in illo foetu $q$ qui ex atro apud nos relicto femine paftim propullulat. Adultze *el mediocres funt vel grandiores. Minuta enim feu attehabus (qui Hefycbio dicitur ärejs urregi, h. e locufie parva) huc non pertinet. Loguimur enim indiffertatione noftra de locuftis alarum remigio inftruetis : Attelabi vero caent alis, nec tàm volant, quàm faltant duntaxat. Difertè ait pliniss (h) : Locuflarum minime fine pentis, quas attelabos vocant. Unde \& Greci interpretes illis non volatum, fed falcum tribuere videntur, quando in interpretatione ver:

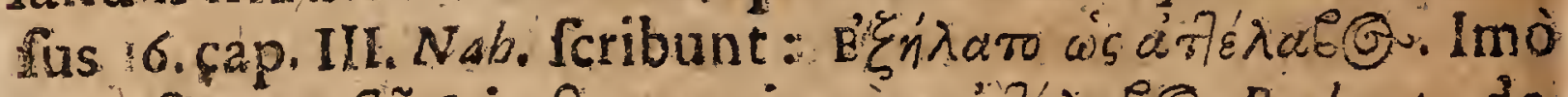

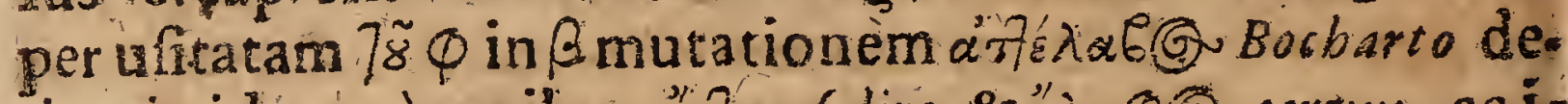

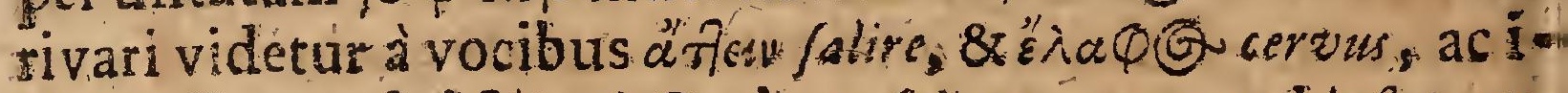

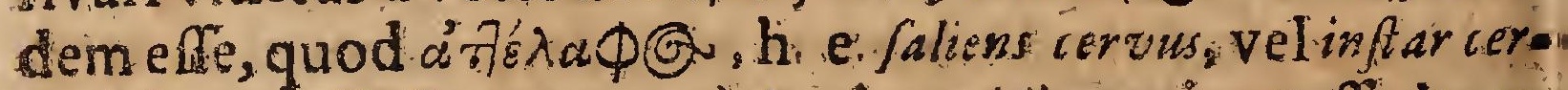
vi faliens. Faluntur certè, "qui attriabram ajunt effe locuAta fetum recens, editum: Quippe apud Ariftotelem (i) \&Plutsrbimm (k) parere, ovaque eniti atrelabi dicuntur. XVII. Mediocrs digiti humani magnisudinem zequant : Cujusmodi noftrates qvoque funt, $2 \times$ apud jobo Zeonem Africanum (1) velut Africam infeftantes; $\&$ apud Zaur. Surium (m) tanquam regiones Polonix fuicimas ano 54. pervagatz defcribuntur. Grandiores autemin india cernuntur, ubi linio $(\mathrm{n})$ tefte ternû́m pedum loner gitudinis funt, ac cruribus fuis feminibusque, fi inaruerint, ferrarum ufum prabent. Eas quoque in Ethiopia grandiores f te oporter, de quibus Frantigus Alparezins. (o) perhibet, vod in ipfurm comitesque involaverint, tantâ vi, ut non liter vifx efent, quàm fi coftas 8 capita: quân lapidum içibus vellent.

(g) Libr:X.c XX1X: (h) libr.XXIX.c.V. (i) libr. V.Hif . Bnimal. c.XX1x. (k) in Ifide. (l) in defeript Afric libr.IX.c. (m) in comm. rertm in orbs gefaum ad ann. 154 I. (n) libr. XI.

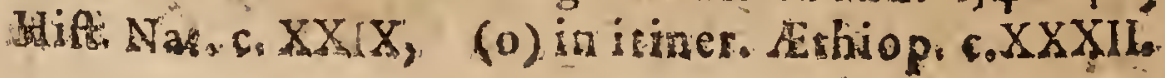


XIIX. Stupenda autem locultarum multitsdo eft quan do agmine factô in regionem aliquam convolant. $\mathrm{Re}$ ferunt friptores complures (p), quòd locufta, quando turmatim provolant, nubis aut nebula inftar operiant folis ridios, 85, ubi fefe demittunt, foli fuperficiem nunc cubito tenus, $(q)$ nunc ad equi ungulam úfque, $(r)$ nunc duorum cubitorum altitudine (s) tegant. Hirc ergo , quòd fua multitudine folemobumbrent, \& ei quafr ve.

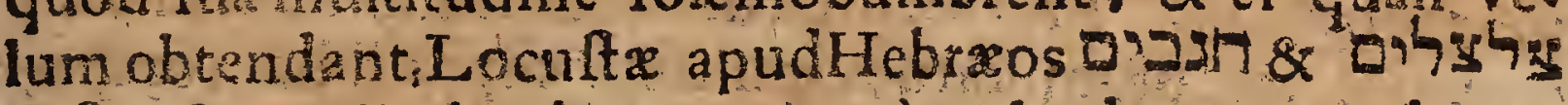
dictx funt. Illud quippe nomen à velo, hocautem ab um bra fumtum eft docente Bocharto in Hieroz part. poft: pag. 444. \& 446 , Aliquando in regionibus Poloniz regno finitimis duorum $(t)$, in $S_{i}$ redienfi \& Lencinienfi orâ a tque Mafovia trium (u), in Athiopia fex $(x)$, in alia Africx parte $(y)$ duodecim mil. liarium Germanicorum \& in Germania $(z)$ tantum traEtum occupavere, quem eques citatô equi curfu unius diel̉ fpatio emetiri haud potuit. Non ita pridem apud nos vefta illa agmina patuerunt duo milliaria in longitudinera ac ferè tot etiam in latitudinem. Atque à longa hac re. rie loc uftx vocantur $4 \lambda 7 \pi$, cbargol. Nam Arabicé chargala eft longum êre, aut longâ ferie ferri \& produci. Aliquando in thiopia arboribus infidentes pondere. fuo ramos fregere (a). In Italia anno is 42 . carum vo. latus per integras fex horas perduravit (b). Hinc por-

\section{F 2 pbyrius}

(p) Plinius libr. XI.c. XXIX Foh. Leo Africanus in defcript. Africa libr. IX. c, LXI. Laur. Surius comment. rerum in orbe gefarum ad ann. I54 I. Fohannes Neuhof in defcript. regnisinsrum pag. 377. Dappersis in Africa fua Tir. Bibyen oier Zanta p. m. 317. (q) Subius 1.c. (r) Franzius Hiffor animal. pert. V.c. iv. de Inf. (s) Francifcus Albarezius in itinerar. Ethiop. c. XXXIl. (t) Surius l.c. (u) Aldrobandius de infectis lib IV. p. m. 423. (x) Fr. Albarezius l. c. (y)Aloyfus Cadamufiss Navigationum cap. XII. (z) Sigifmund Son Bitcen in Spis.

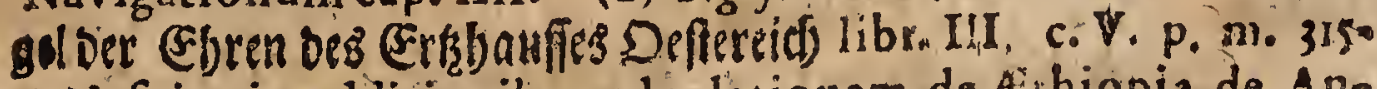
(a) lefuire in additionibus ad relationem de Airhiopia de Ane nis $1607 . \& 1608$. p. 314.6. (b) Menochius de Remed. Recup:

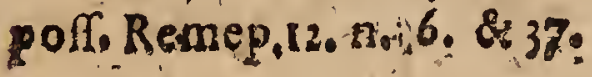


phyriss Pythagoricus (c) \& Theodoretus (d) locuftarum agmen

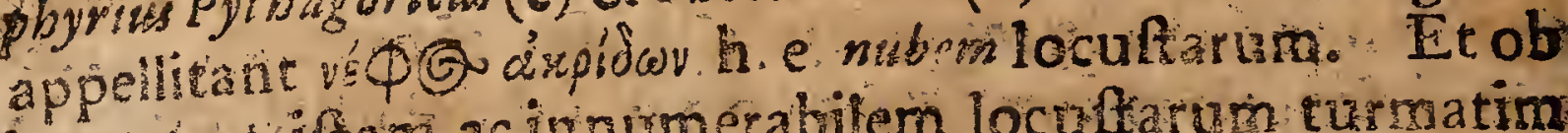
ingenten iftan as innumérabilem locufarmm turmatim provolancium copram ipfa nomen Hebrem $1 \mathrm{~s} 2 \mathrm{~s}$ for titz cunt : pout A6enefrs in Leviticum vocem hanc

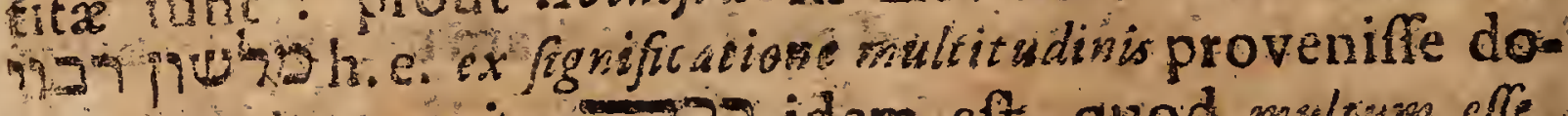
sef. Verbum enim 727 idem eft, quod maltum offe. * maliplicar. Imó locútarum multicudo abiit in pro. verbium, ita, ut multarum gentium copiz illius comparacione in varis Srriptura locis (e) fignificentur.

Xix. Uliman quod attinet affectonem, COLO. REM videlice, noftrates locunx ratione illius valde variant. Alizfunt virides, alix lutes, plerzque cans. mnium alx maculis nigricantibus multis difinct $x$ funt ac infgnita, quas pro liceris, qua nobis fint igno. tx, nude vulgus habct.

$X X$. Sic ergo locultx, ut alis varis multisque modis, ita etiam colorediftingvintur. Ipfa Scriptu \% (f) varia mundarum locultarum genera enarrat, dum non cancum aliam vocat $27 x(A \times 6 c b)$ aliam $\square$

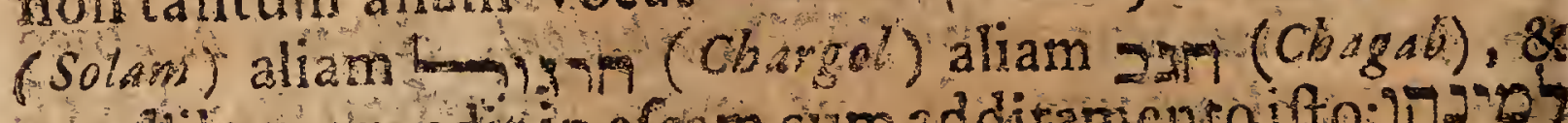

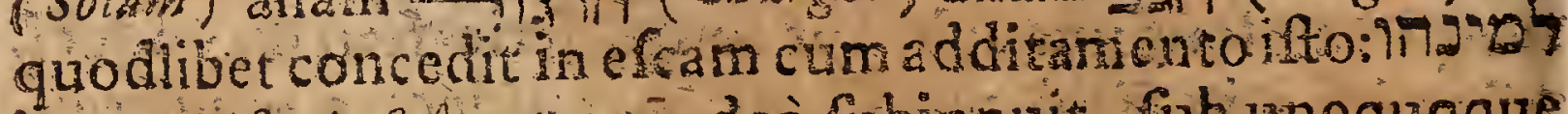
1h. ecsmperefin, arque adeo fubmnuit, fub unoquoque plures fpecies fpecialiores comprehend. Quanqua quatuor lla gertera Latinis verbis difingui non porfint, s idcirco in plerisque vernaculis verifonibus Hebraica. rocabila fueint retenta. Quidam triginca locutsarum generatradunt R Ananas Fezzasus (g fex in Mauritaina fpociss fe vidife Francofurti ad Monum retulito. Aoud Aldrovardum (h) ulkra XII figura earum somparent. Bocbar.

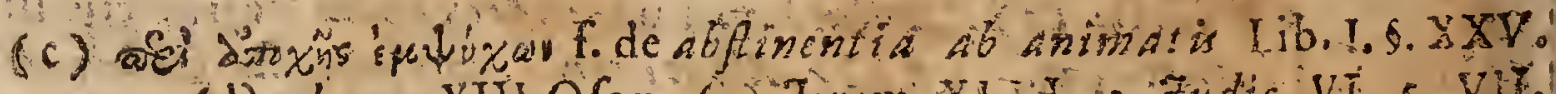
(d) ad cap. XIYI.Ofea. (e) Jerens XLY, 3. Judic. VI. 5. VI, 12. (f) Eebit. XI,21 (g) Vid Ludolfus in comm, ad Hifto

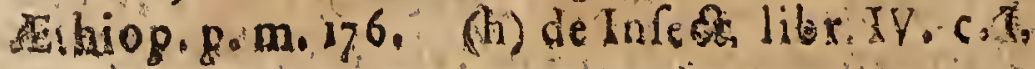


Bockstus (i) in Hierozoico decem illarum nomina in Fros phetarum fcriptis obvia, diverfasque fignificantia fpecies. cnumerat \& interpretatur. Gemarißs (k) octingenta lo cuftarum mundanarum genera commenti fune, qux Is. raëlitas Babylonem fecuta fuerint. Afr, ut recte notat Ligtfootus (1), acutus certè foret ille Lexicographus, qui fingulatim hafce fpecies fuis nominibus defcriberet. Certum interim eff, quọd locurtarum genera varia con ftitui queant. Aliz enim funt alatz, alia alarum expertes Alata vel habent $\bar{\varepsilon} \lambda u z \xi a v$, vel ejusmodi vaginâ. in qua recondant alas, carent. Quz deftituta funt ejusmodi vaginâ, vel quatuor habent alas, vocanturque reree.

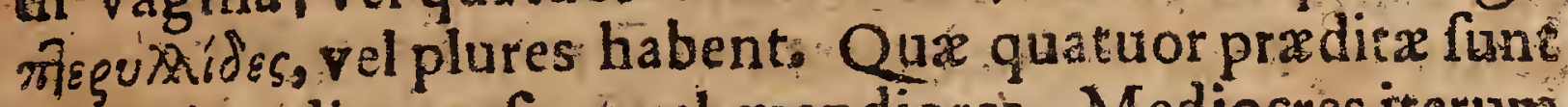
a lis, vel mediacres funt, vel grandiores. Mediocres iterum funt variigeneris : Quadam funt virides, aut lute 2 , aus canx, occ. quadam glabre, alix hirfutx: quxdamcum cauda, aliz ujus expertes. Cujus autem generis noftrates fint, ex fuperiùs dictis valdè manifeftum eft.

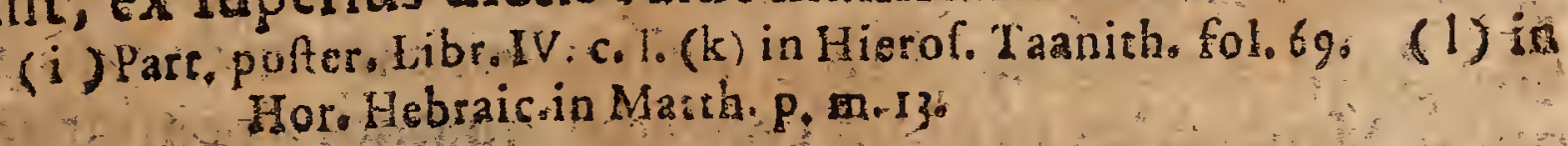

\section{Caput IV.}

\section{Ad quid profint LOCUST F,}

quidve noceant, $v$ de vavio adrer us eas grasedits exponit.

I.

Neer tot locuftarum genera reperiuntur etiam, noon qux faltern humano geneni riocent, fed ufum quoque a: liquem praftane. In Irdia pragrandium fosuftarum crura \& femina, ubi inaruerint, ferrarum vicem in se domeftica 
fuftinere traduntar (rn). Narrant quoque Aviffoteles (n) \& Plinius (o)locuftas ferpentem, Eaucibus ejus apprehenfis mordicùs, neçare Scribit \& Arifototeles ( $p$ ) alibi, in Argo locuftax genus effe, oregrzofad'xoy nomine, quod, quamprimumforpium viderit, in eum infurgat. Cui narrationii tut facilius habeamus fidem, Simon :Majolus, E Eifcopus Vulturiacenfis (q) facit; qui fuum ait olitorem, ex agro ve: nientem, locufan confpexife, qux ferpentem gutture apprehenderit, atque ita citra pugnam interemerit. Refert infiper Laurentius Surius' (r) locuftas illas, qux an $154 \mathrm{x}$ - regionés Polonia regno finitimas váftavére, damna data aliquô beneficiố compenfaffe, sùm pecudes porci inprimis, mortuis ipfis avidisfimè vefcentes, fe mirè iis faginaverint.

II. Obfervamus nunc potifimum, quód locufta. rum efus in îs, qua valad ortum vel ad Auftrum funt, regionibus, imo in Gracia fit receptifimus: Hieronymus (s)

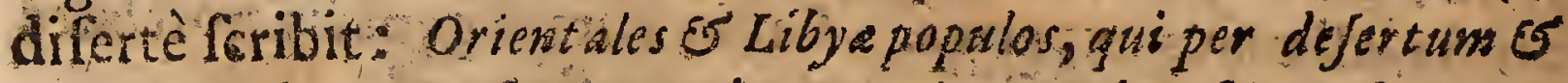
eremi Daftiatem locueft arum nubes reperiuntur, locuftis vefci morio eff. Judxos olim ciboifthocfuiffe ufos, tum inde liquet, quod Mofaica lex in efum concedat quatuor locuftarum fpecies, arbeh, Sol-amm, chargol, \& Chagab, tùm ex eo apparet, quòd Talmudici Dociores (t) prolixè difputent, quibus notis dignofcantur locuft $x$ mund $x$ ab immundis, h. e. quas efitare licet, ab iis, quarum efum Lex interdicit, Et hodienum Judxos in Mauritania degentes comedere de locuftis, tariquam de fpeciebus in lege non prohibitis, $R_{0}$ Amanigs Fezzamus apud Ludolfum (u) aperit. Sic \& Beda (x) ab E. pi/copo Arcbulpho, qui ad ea loca peregrinatns erat, inftruCtus, Eutbyminus Zigabenus(y) facobus de Vitriaco, Ptolemaidis

(m) Plin lib. XI.HiA. Nal. c. XXIX. (n) libr. IX. Hift. an im.c. VI.(o) loc. cis (p) in/libro Mirabilintm. (q) in Dieb. Canicul, iujtio Colloquit $X$. (s) in contment rerum inorbe geftarumad amm. is 4 f. (s) libr.II in Jovinianum cap.VI (c) in Tract. Cholin. cap. IIl fol 6 . \& $66 .(u)$ in comm. ad Hift. Ethiop. p. m.177.(x) dolocis fanctis c. XIV. (y) in Mattho c. III. 
Epifcopus, $(z)$ \& Adamnanzs Scotus (a) pari confenfu te ftantur, usque ad hodiernum diem locuftas in Judza 8 Palxftina comedi. Olim quoque gens Ethiopica, Silis 鹿thiopibus finitima, per totum vitx tempus $\&$ in annua alio: menta vefcebatur locuftis, quas eô pacto aucupabatur, ut fumofam materiem in convallibus congeftam incenderet, fumoque tenebras offundente delap fas colligeret $(b)$. ar. this (c) 2 locuftx in cibo grasx fuerunt Eas hodieque 0 mnes \& finguli Arabes [d] opulenti pariter ac pauperes, cum maximo appetitu, Sivenfes (e) velut cupedias (ols fecfer bifitin) Mauritani (f) tanquam pullis columbarum fvaviores, quarum tota plauftra à rufticis tefte Clenaráo Fezam convectantur, nec nor Egrpti (g) comedunt. Gracos quoque vefcilocuftis confuevife quondam, non unô comprobatur argumentô. In Aristopbanis (h) Achar. nenfibus Boeotius rufticus inter cibos venales, ques Athe.

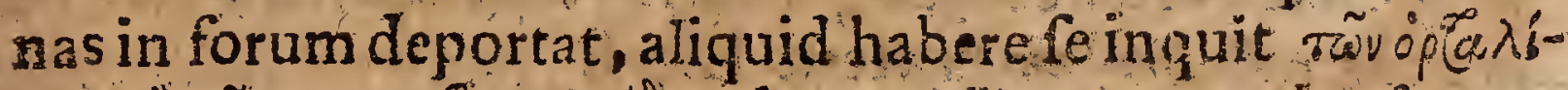

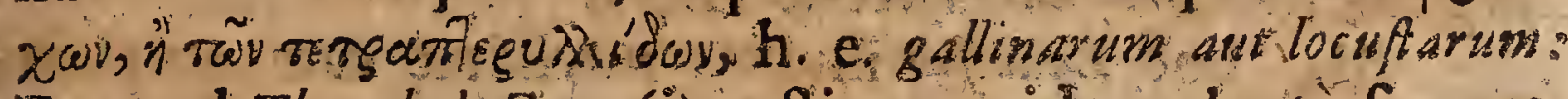
Et apud Theophylactum (i) rufticus quidam, laute fe exce-

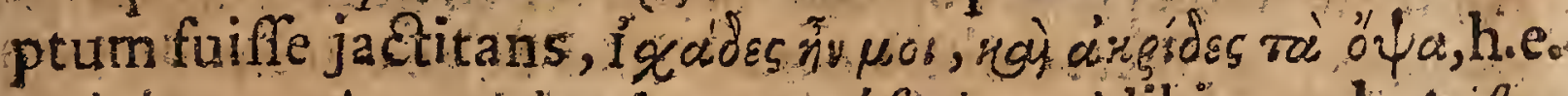
Habebam caricas of loculas pro obfosio. Alibi apud Arifte. planem (k) fic fribitur:

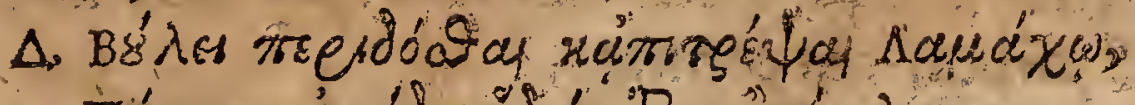

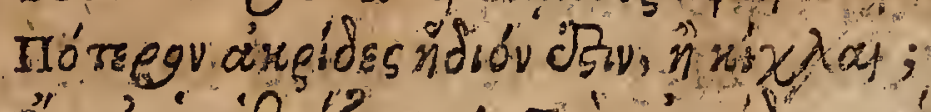

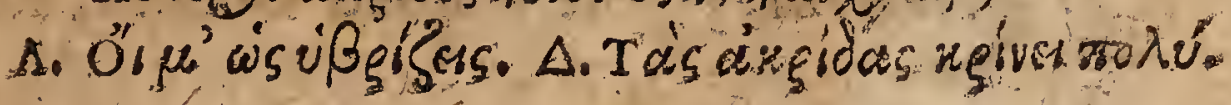

D, Fis sir

(2) Hiftor. Hierofolym. c. LXY (a) lib. If, de loci fanctis cap.XX.(b) Strabo Geog. lib. XVI. p. m. 531. Dindorus Siculus libr. III.Bibliorhec.Hift r. p. m. 162.162. Agatharchides apud Phot. Biblioth. Cod. Lr. (c) Plinius libr. XI hift Nar. c. XXIX (d]jofepbus de S. Angelo Tolofanas in Gazophylacio Perfico in voce Locufta.Petrus Kirftenius ád cap III. Mattb. fFob. Leo Africanus: in defcript A frica libr.IX.c.LXI Demir in capire de Locuft is apudBocharím in Hieroz. P. I.Lib.IV.c. VII. (e] Johannes Neuhofin defcripr, regni sinarum p.m. 37.7. (f) in Epit.L I p. m. 73. (g) Hermol. Barbar. corollar. in Dicfeoriden. CCLVI. (b) A C. IV. Scen. 1. (i) in Epiftolis \& quidem in Epift. cujus 6: $^{\circ}$ mour initium (k inA chamen fbus Åtus quarti Scena Septimâ 
46.

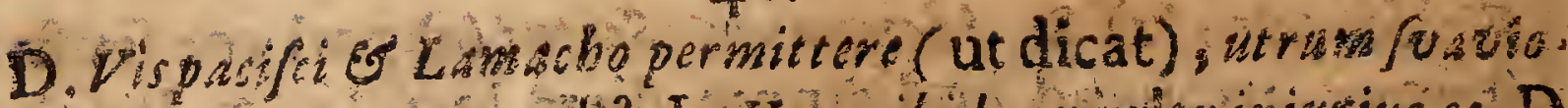

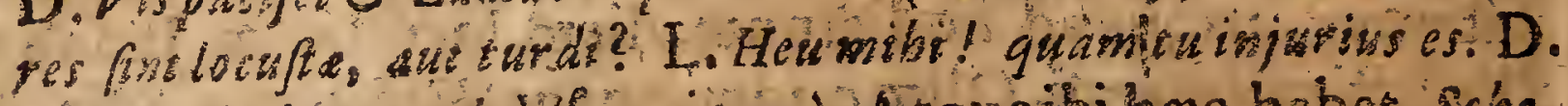
Lucufas judicat malto (Luaviores). Atque ibihx haber sciso

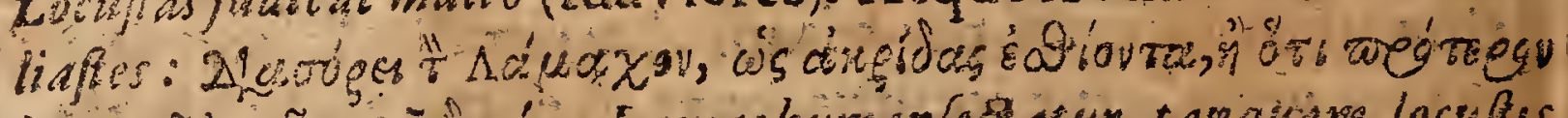
दथ wefenterta au qura anted vilicibo ufus fuerat. Solet \& ad pro. bandum locufarum cibum apud Gracos receptum pro. duci Galens, quinter cibos tardifimè alentes recenfet

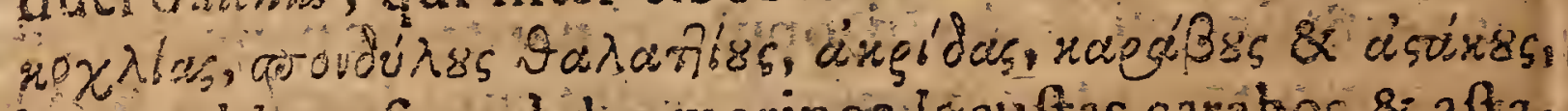
h. écochleas, fpondylos marinos;locuftas; carabos \& afta. cos. Afrin ito Galeni dicto legendum mihi videcur xa.

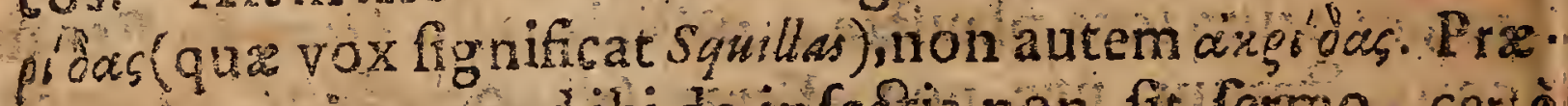
terquam enm, quodibi de infectis non fit fermo, certe alias apud anforlem $(\mathrm{m})$ \& Atben oum [i] quardo pifcum

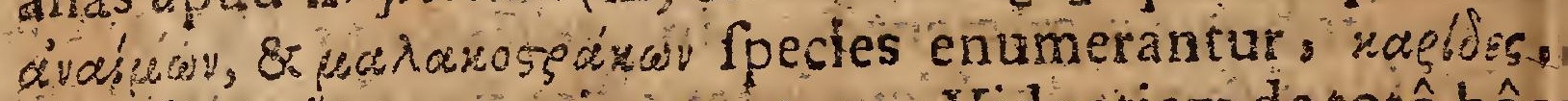
ráphri \& azra conjunguntur. Vỉe etian de totô hố argumentô Drufrum Pracerit. Lib. I,

III. Imò Ludolfus illufris novifime eam amplexug eft fercentiam, quod Selawe Num. XI.31. quas vulgata per - oturnice ceplicat, multo commodiùs \& genuiniùs de locu. fis, quan ds corumicibus, aut alia avis fpecie intelligi porint Cortas autem affertiones fovet, quibus hac ipfus opinio confrabilitur auc conftat:

1, 7\% N Num, XI, 3 , effe aliquod volatile, feu vo. lucre:

11. Non efle certum, Selawas illas fuife cotur nices,

11. Non effe probabile, quòd fuerint cocurnices, fed probabile potius effe, quod fuerint aliud quoddam 9? , feu aliud arimalium solatilium genus,

1Y. Ea, qux de selawis dicuneur, non poffe alicui dam volucriapplicaricommodiùs, quàm 10 . cuftis.

Pri-

(1) Vid Ifacuscafaubaras in Exercit.XIII ad Annal. Ecclef.Baron. (ii) Mibr.lF. Hiftor,animalic.tI. (n) libr. If. 
Primam affertionem neno negat, qui contextum ctenit Sic \& fecunda affertio certa ef. Nam (a) cùm genuina vocis illius fignificatio deperdita fuerit in captivitate Babylonicâ, interpretes Orientales retinent vocabulum Seleswa fed non inelligunt, per aliam quippe vernaculam vocem haud interpretati; Occidentales verò folius fofeptibi per co: turnicem explicantis auqoritatem fequvutur, cium tamesz reliquorum Judrorum turba aut plane diffentiat, aut certè de ifto fignificatu ambigat. $N e c(\beta)$ coturnicis fignificatus ex aliis interpretandimediis, e. g. collatione cum locis Scris pturx parallelis, frgnificatione radicis aliarumque verfonum Orientalium infpeaione, erui poteft. Certè fi Exod. XVI 13. \& P . CV, 40. confulas, nulla peculiaris reperitur circumftantia, nifif qvòd in jalm allegato Pfalmo selau dicitur -251 712 volatile alatrm, id quod ctiam non coturnicibus folis, fed alirs quoque avibus, imò locuftis tribui pereft. Ac Lexicographi vocem the fine radice proponunt, 2 , f opinionem Bocbarti à radice Thes (abundavit) defle. Gentis amplectamur, nihil hinccolligitur aliud, quàm Selayas in magna copia adventâfe : Id qvod iterum non coturnicibus folis, fed aliis qvoque volucribus, acin primis locuftarum inefabili agmini accommodari pe. ceft. Reliquz etiam verfiones Orientales vocam ise fine expofitione aliqua adhibita retinent. Tertiam af fertionem Ludolf w ex eo firmat, quod, fi textum de coturni. cibus interpretére, non tantàm incommoda multa à mira. culis in onanibus fere verbis cumulatis oboriantur, fed \& bicubitales acervi, collectio à Mofe defcripta, avolandi mo. d9, ac deniq, commemorata menfüra \& expanfio cocurnicibo minime conveniat, Quartam deniq; affertionempér remetio. Dem aliquam conftabilit. Qvodcunque enim volatile nomina. veris, nulli commodiùs attemperari poffunt en, qva de se: 


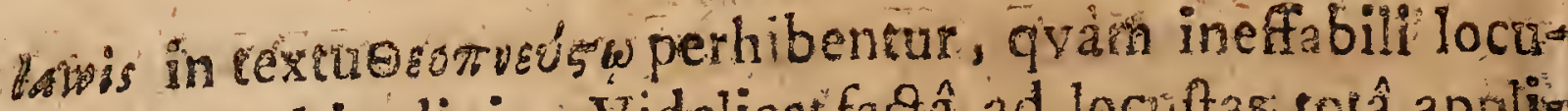
ftarum multitudini. Videlicet facâ ad locưtas totâ applio catione hiftoria facra $N / m$. XI, , fic ex mente Ludolfinterpretanda venit : Et ventus. Aufrelis, ab onmobusmegidialis plages

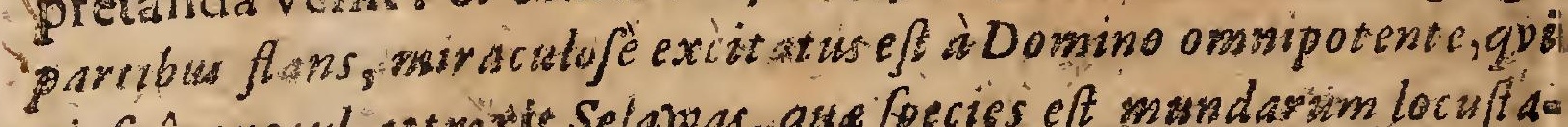

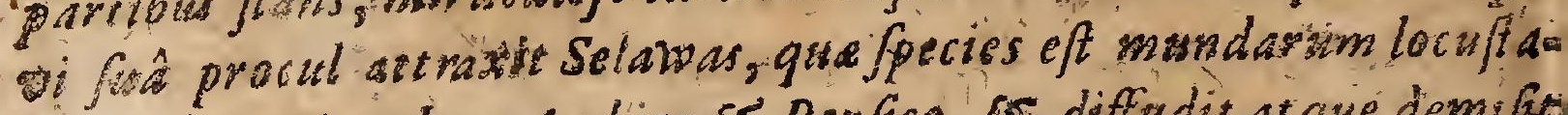

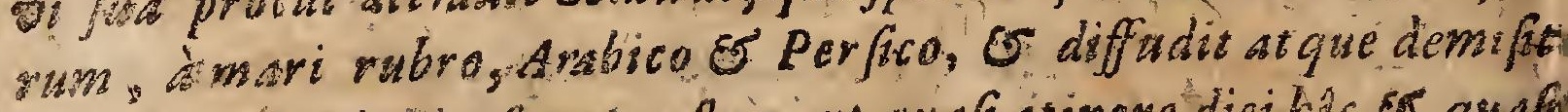

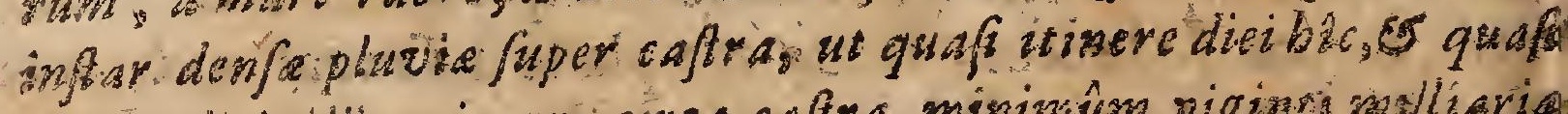

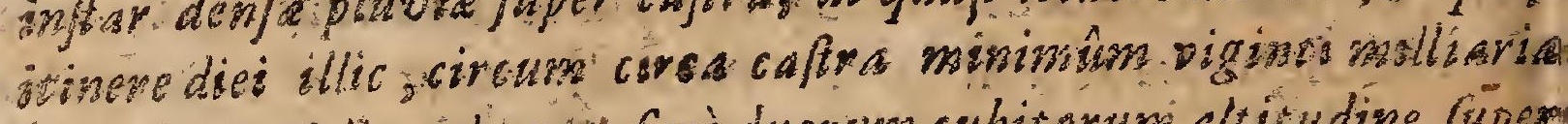

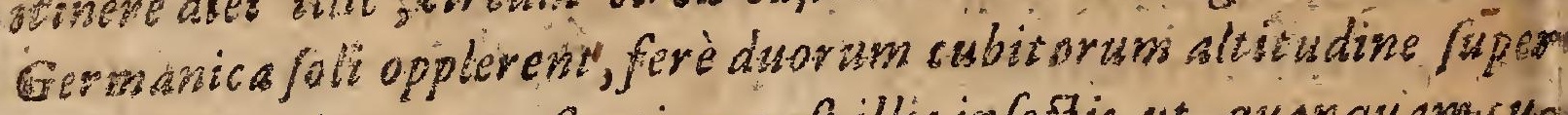

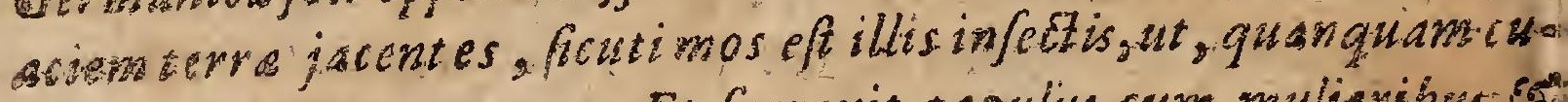
mulata wise maneant. Et furrexit populies cum muliexibus

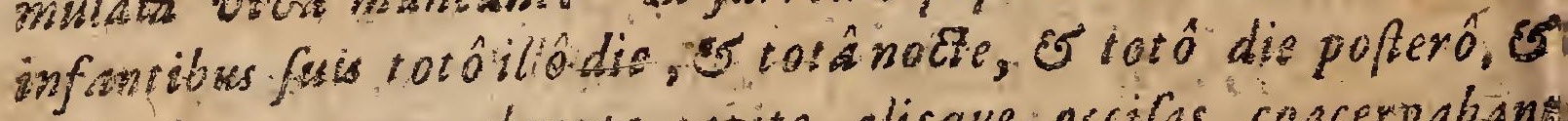
colligebant, atque abrepto apite alisque occifas coaceryaban

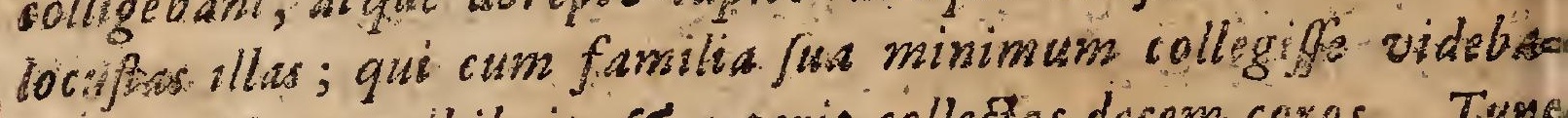

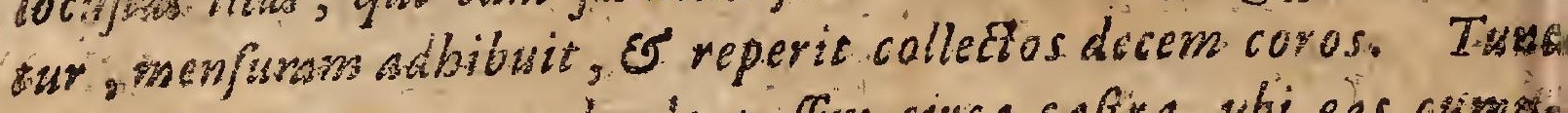

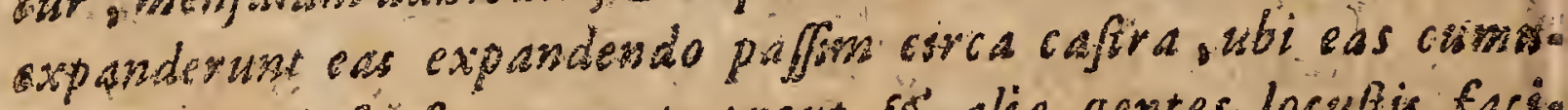
liaverant, E fic focaderint, prout of alid gentes locufis facs

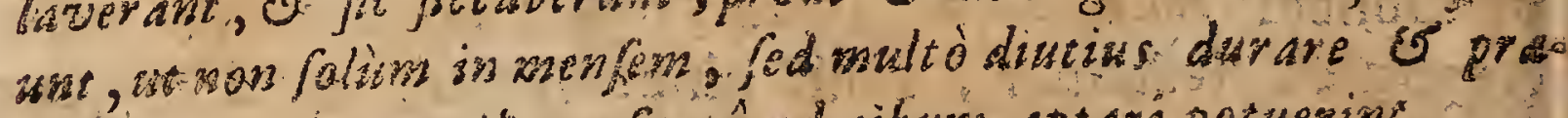

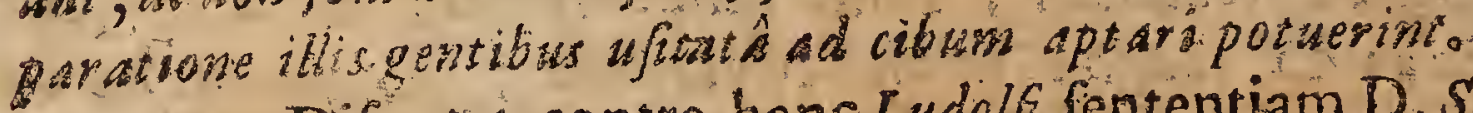

V. Difpurat contra hano Ludolf fententiam D. Samise Andire in difguifitione Manufcriptâ, cuius mentionem feci fü. perius. Nos verò opinionem illam in præfenti argumentci Momgnare fuoerfedemus. Quippe ipfe Clariffinus Andre de fulgatâ ilấ fignificatione, quầ coturnicem defignare pucatur dubitat, easque Ludolfo opponit rasiones, qua nondum evincurtillud quod demonftrandum esat: id quod aliâ oc cafone, fervatis modefiz fantioris legious, copiofius oftendemus. Neque verò Lädalfiana expofitio omne tunc factum miraculum negat, aut fidei ac religioni Chrilianæ prajudicas fuicguam. Erfich de locultis hiftoria ifthec facracci piacury vis tamen miraculi ac potentia virtusque Numinis infinitin 
infinita in eo eluxit, quod exremorifimis oris brevi tertpons tractu illa locuftarum nubes fuerin advocatr, ventusque ab omnibusmeridialis plage partibus Aans foló Deinutu fi concitatus. Et huc quoque (pectat, quod B. Huteruo) advo.

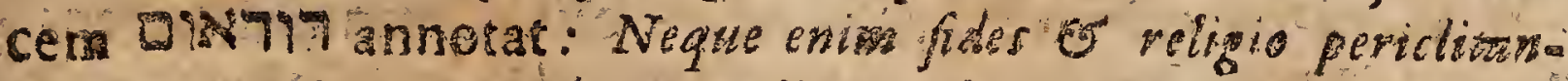

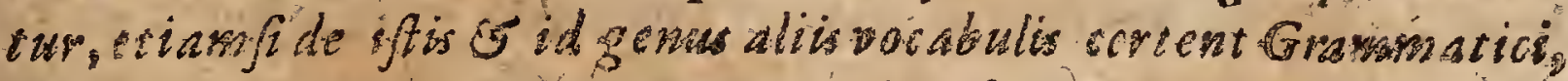

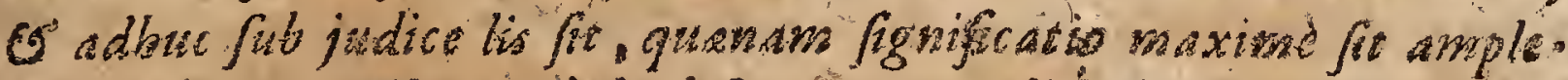
Eenda. Accedit, quòd obfervatum mihi fre, Jonatbanem in paraphrali ad Exoh. $\mathrm{X}$, 10. docere, co quoque tempore, quo in If gypto commorat fun Ifraelita, locuftas ibidem comedi folitas fuife. Nam ad locum illum Scriptura, ubi ventus a Deo concitatus abripuife, \& in mare rubrum precipitafe di citur, quicquid in Agypro locuftarum erat, ita, ur neuna quâ.

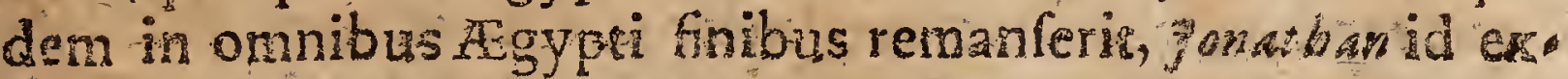

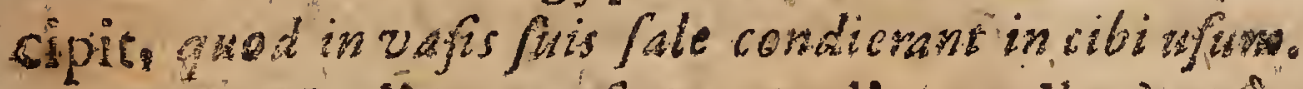

VE. Varii autem fuere modi populis áxesdopázobs reces pti quibus locufas necatas a efum praparânunt Prifi Ethiopes $(p)$ \& hodienam nonnulli incola palælina (q) fumô fic cant. Sic 8 antiqui fethiopes (r) fuper confertis locutarum acervis affuderunt falfuginem, debitagve effecerunt mace. ratione, ut fapor accommodus fit, 2 citra putrefactionem be ne longum tempus hoc fallamentum duret. Arabix deferta 3. Libyæ populi (s) elixas, vel ad folem defoccatas in farinam tundunt, atque comedunt. Arabes ( $t$ ) alas a pedes abripi. unt, ac reliquum copps collo infpendun, folique illic loco. rum latis ferventi per aliquod remporis fpatium exponunt, is tum dernum, ubi incaluerint à fole probè, fatisque intumue. ninr, avidesefcences. Ali Arabes (u) coqvunt in aqua cum pauco, fale, Nonnuli Arabum ( $\mathrm{x}$ ) cogume, \& arefachs

$$
G 2 \text { deinde }
$$

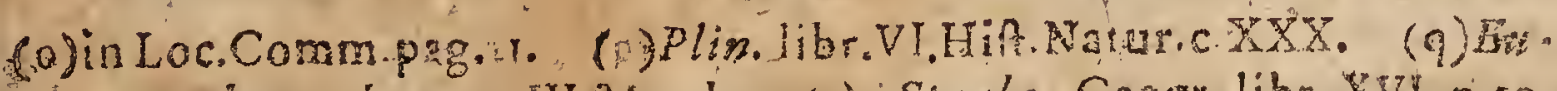
thym. in cap. III Math. (r) Sisabo Geogrolibr. XVI. p. 59

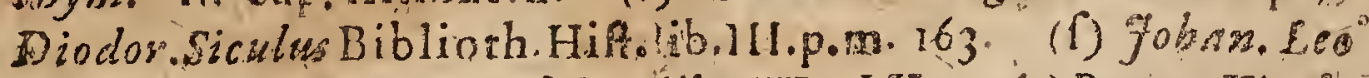
Africanus in defcript Africalibr TX.c.LXI. (JPetras Ri rfte.

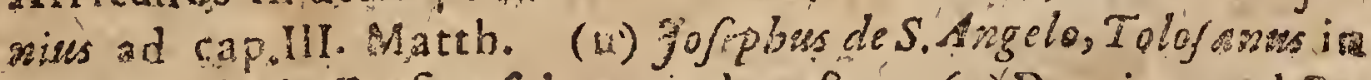
Gazophylacio Perfico fub roce: lacufta. (x)Drmip apud Bges

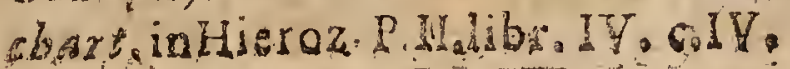


deinde contundunt \& cum adipe mifcent.Mauritani(y) nithil abjiciunt de illis, niff caput,alas, \& pedes: Per horam coquunt cumfale in aquam bullientem conjectas, ac pofthac cum pipere falęaceto comedunt. Quidam inPalæRina( $(2)$ percoquuntoleô.

V71. Hinc igirur, quòd locuffe olim Orientalibus gen. tibus pro clulio fuerint, frntque inter cibos Judais lege conceffos, colligimus non immeritò, quòd quando án édes (locu/2.) Johannis reg \$y fuiffe dicunur (a), perfirendum frt in ordivarîa ac ufitatâ vocabuli corre id (a) fignificatione, nec quiç̧uam caufa appareat, cur Baptifte cibum aliud quid, guàm vola. tile iftud infesum, fuifie cenfeamus, Scite Cefar saliger (b)

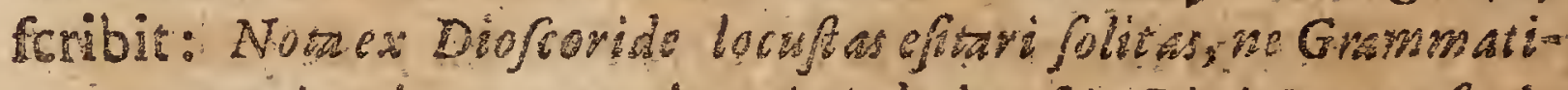
corum perinacia pergat ineptivel de locofis Divi Precurforio. Aique eandem, quam tuemur, interpretationem amplexitune Theopbilus Antioclowass, Origenes, Hilarius, Chryfoftossus, (C) Ambrofus (d) Clemens Alexas drinus (e) Elicronymus (f), Augisfrimus (g), friptores deniqve omnes, quotguot If fdoró Pelafiro. th $\left(\right.$ h) diverfum fentiente vetuftiores funt, fi unum $P_{\text {aulinum(i) }}$ aliam amplexum fonentiam excipias.

VIT. Us attem temporibus fubfequentibus interpre: res varii ab uficata \& ordinariâ vocabuli àrpide fignificazione abirent, atqve in omnes formas fe tianstormarent, verBa Evangeliftarum alio detorquentes, non aliud judice Do Qựmê Vesfio (k) fecit, guam quvòd nefcirent, multis olim lo. cuntás fuiffe pro cibo hodieque efle. Ac feptemalias de cibo. Tohannis fentencias percenfet gob. Caßpar Spicerus (1), quas mawimaw partem Dn. Profes in peculari quadam de fobanne $E$. remita nuper confcriptâ differtatiunculâ examinavic.

IX.Inquis: Aunteritas effe debebat in fohanisis vieuth? hac auté nonfuiffet, fiefitaffet locuftas, quippe quod ipí com. mune

(y) Ludolfus in commeniar.adHifor, Ethop.p m. 170. (z) Beda de Lo-

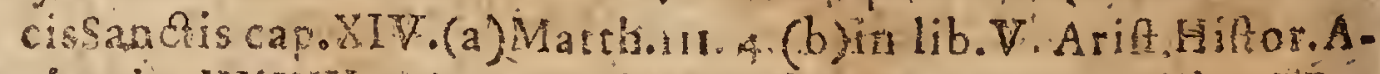
nimal,o.XXVII. (c) omnes in Math. (d)in Lucam(e)libr.M.P. dagogi (f)lib.t.in Jovinianum, \& e p.XXII: ad Marcellam- (g) Hibr. X. Carfefionum cap.XXXI,(h) Hobr. Lep.V.\&CXXXI. (i) in facro pocrat.de Joh $B$ aps. (k)libr IV de or \& rogr. idol:

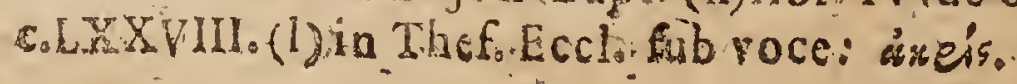




\section{3.}

mune foret cum aliis tenuiter victitantibus, terpondet $1 / \mathrm{fas}_{\mathrm{N}}$ Trus Casaborsu (m), aufteritatem notatam in Johatime non in eo effe, quod locunas ederet, fed in eo potius, quod folls losiffis vefceretur, \& melle fylveftrio. Addimus, Johannem comedirfe locuftas non oleo perceetas ac cum adipe mixtas, nec cum pipere, fale, \& aceto, fed rudes $8 x$ ad folem deficcatas :qux pro: feerò eft magna in viqu aufteritas.

x. Non folù autem Deus, ut hominibus fint cibo, fed 8, ut fint eorum plaga, immittit ftupenda ifta locuftarum agmina. Inprimis, quando ad nos cibum cjusmodi naufeantes \& averfantes provolant, procul dubio funt animadverfio Dei innoftra peccata, \& infigne, ut maturè refipífcamus; incid tamentum, ni deteriora pati velinaus. Plimius (n) difertèvocat Desrum irépeffem.

XI. Actocius graflantur in fruges, \& ea, qux in ufus ho. iminum neceflarios gignit humus. Firmantur hac de diro ifthor mulo tùm octayâ Egy ptiorum plagâ (o), qux per 10cuftas fuit, tùm foölis (p) Prophetiâ, ubi guis famis ab Elifro pradiaz modus hit futurus, refertur. Vesba Prophete funt:

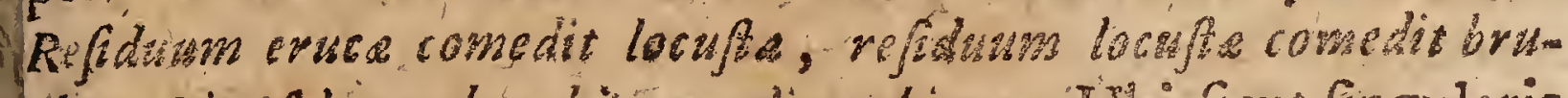
chas, Es refidium brucbì comedit rubiga. Ubi ficut fingularis numerus pra plurali , ita nare Hebraorum, ingrimis Prophe tatum, prafens tempus pro futuro fumicur. In Hifforicis etiam externis abunde eff exémplorum. Extat apuditubertum Golzium nummus argenteus, cujus in unâ parte effît um eft caput muliebre fpicis triticeis cinctum, grod saput eftCere.

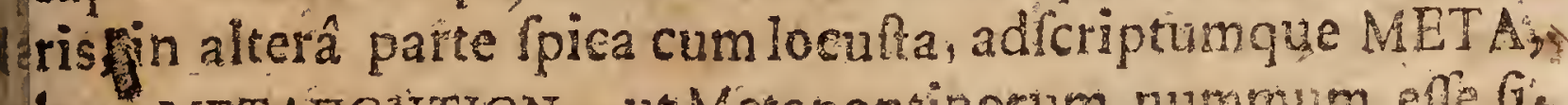
h.e. METANONTISN, ut Metapontinosum numbum efle fir gnificetur. Videlicet fertiles Metapontinorum agros locufra ingenti clade depopulabantur, fed confultô tanden Oraculố Delphicô, \& placatô (utipfi credebant) Numine tanta frugum peftis fublata erat. In Ethiopiâ (q) frpiùs non déferta \& $a^{2}$ -

(m in Exerci XII ad Anal.Ecclef.Baronii k) lib XT, Hil. Nasur.

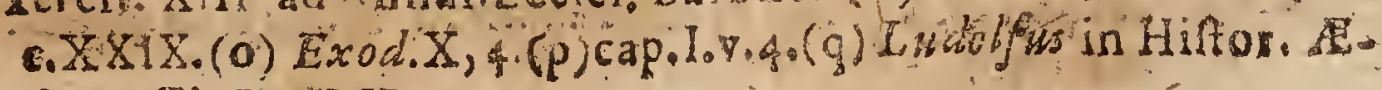
thiop.lib.I.cixlII. 
Tenofa loca, ut ferpentes, fed arboribus confita atque frugibus culta quærunt locuftie: non herbas, non frutices, non arbores intactas relinqunt; quicquid herbidum aut frondofum ent, ab iis arroditur, quafi igne tofum effet: Cortices arborum dentibus mandunt, \& fic now unum tantùm annum nocent. Hinc \& Ethiopia (r), licet magha ejus fertilitas fit, fape laborat fame. Anno I 4 r. ownes res humi nafcentes $\checkmark$ Prấruntad radices ufque (f). Anno 1543. locufxills, qua per Mllyricum ltupendis agminibus in Italiam convolârant, in agris fruges \& regetes, in pratis gramen, in arboribus folia omnia ocyfifmè devorârunt ( 8 ).

XII. Nos autem in medio ponz fuz atu quibusdam blandientis Gratix radiis Deus refecit, quando hec xhate in iis, qvas peragrarunt, or is diu conquiefcere agmina illa fivit,nec antè, quàm cœlô quadantenus frigelcente, quó jam magnam partem exting vuntur, in hos immifir rraeus, necomnia permifit vaftare, $f e d$, ut vitibus arboribusque parcerent, nutu fuố divinô jufit. Prohibcat \& Deus, ne, quam ex atro femine poft fe reliquerunt, propago hic loci crefcat, futurumque everat annum.

XIIL. Etfi verò tot mala damnaque dent locuftr, va. ria tamen contra eas remedia deprehendunzurlac cogitari poffunt. Non autem excommunicationis fulmine vibrandas putamus locufas; prout olim ralix incola cenfurisEcclefiaftcis contra impiam locufarum vaftationem faviendum decre. verunt (u). \& Batbolameus Chaffanan, TCtus Burgundus (x), eum fugandi arcendique modum adprobavit. Hunc, inquam, propulfandi modum nequaquam collaudamus. Excommunicatio enim en hominis Chriftani à corpore Eccle. fix vel faltem à perceptione Sacramentorum ejus exclufio (z).

Hixc

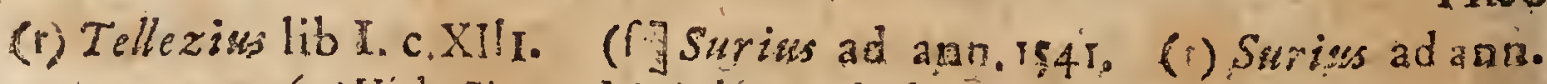
1543.(a)Vid. SimonMajolús in dieb. Canic. T. de Irif, p.ror. (x) Confil.I. (y) Vid Canif. in frmm. Jo Canon.L.3. tit. 3. D.2.Spg-

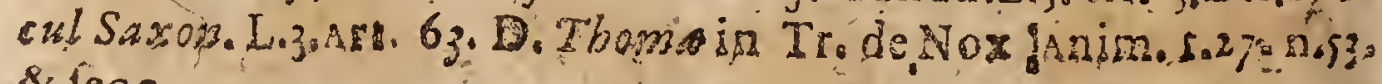
\& fẹฺุุ. 
65.

Hac aucem ad locuitas minimè poffune apphicari. Suppetung autern alia contra peltem illam remedia. Quippe [1] varia aves pro nobis contra locuftas militant [2] conceffa eft hod mini poteftas rumpendi ova, ne generentur inde alize [3) da ta eft nobis facultas genitas variis modis necandi. [4] venti guandoque ingentem copiam in maria aut Atagna precipitants [5] frigefcens colum vivas extinguit.

XIV. De his \& pluribus aliis contra locuftas remediis, nec non de oriuac pyejagio earum, ut \& deco, quod fecun:dum jus natura circa damnum ab infecto ithoc datum obfervari debet, exponendum effet copiofius. Aft, cum hoc noftrum fpecimen præterfpem in tot pinas excreverit, hic pedem figimus, lectorem benevolum ad differtationem alian, guz intra odidum à Dn. Prefide procurabitus, officio: sè remittentes.

\section{Iantum hac vice.}

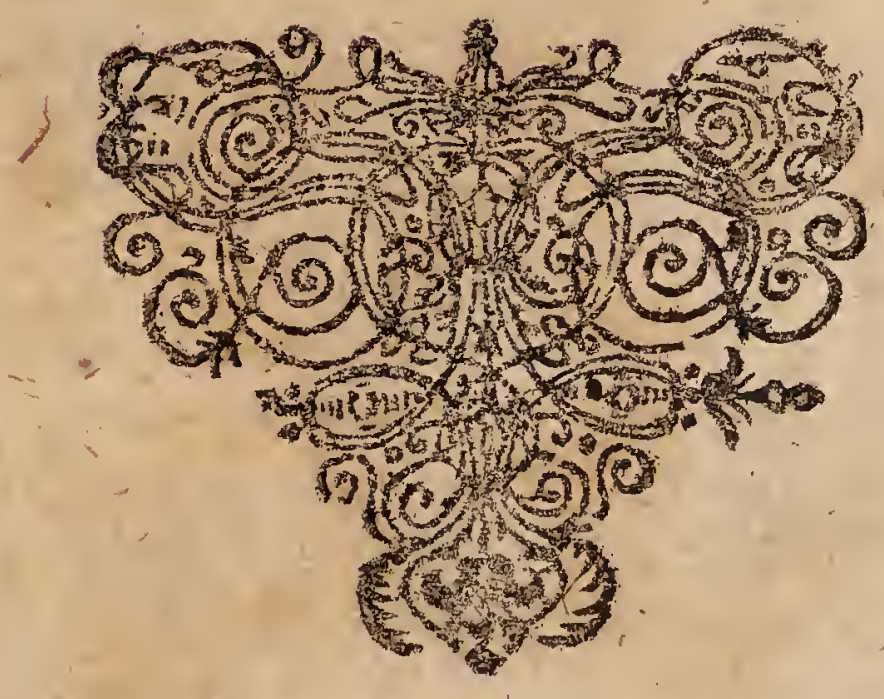




\section{-}

(1)

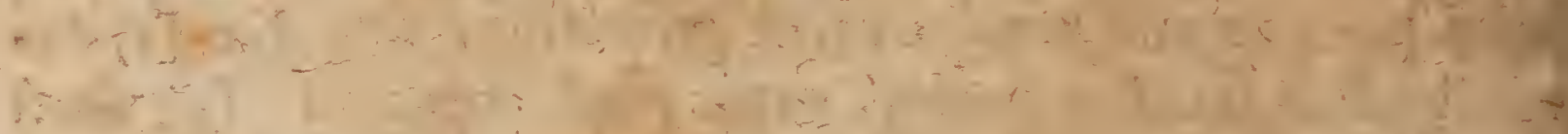
S.

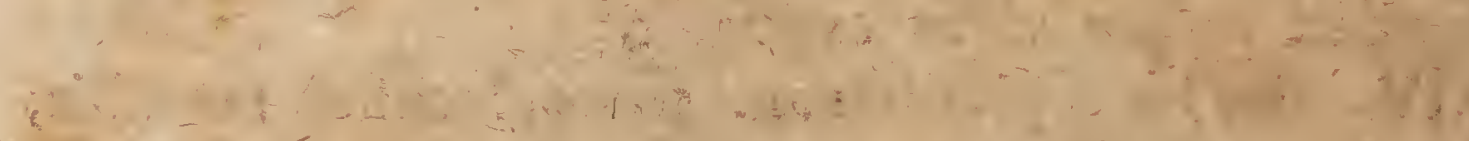

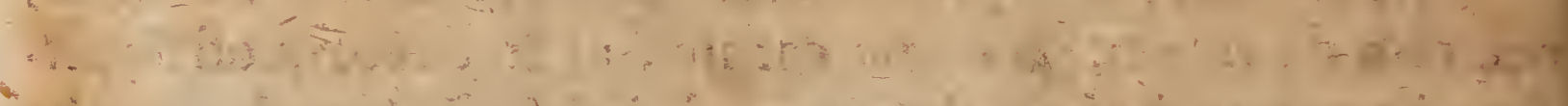

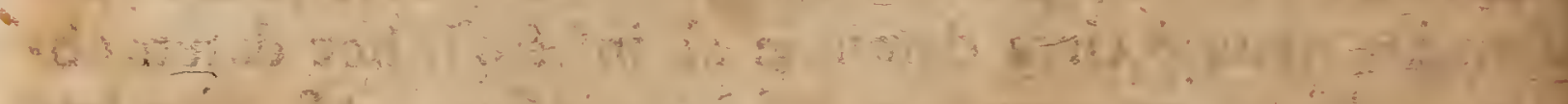
a

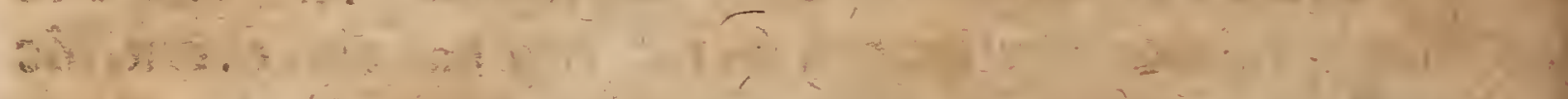

-

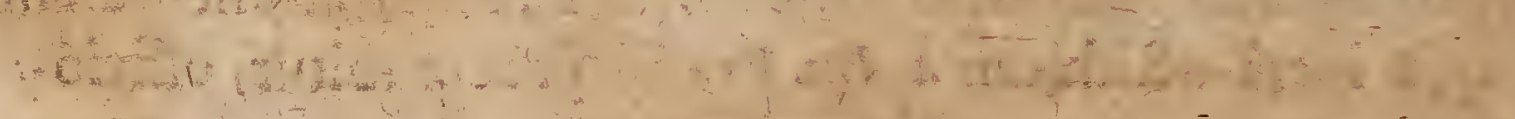

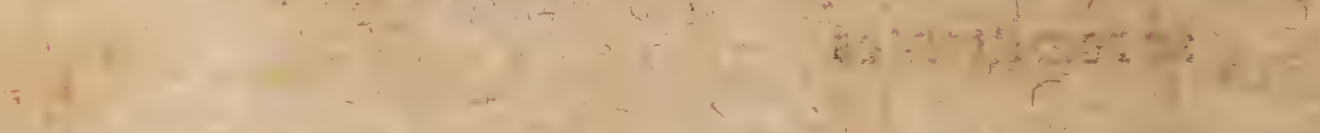

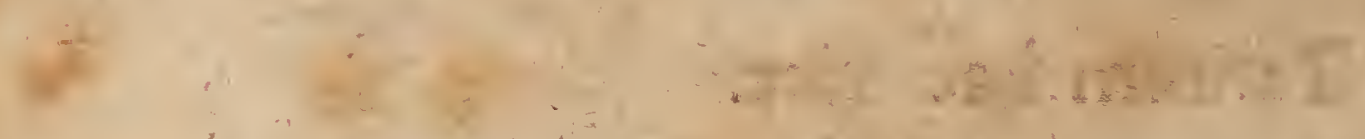

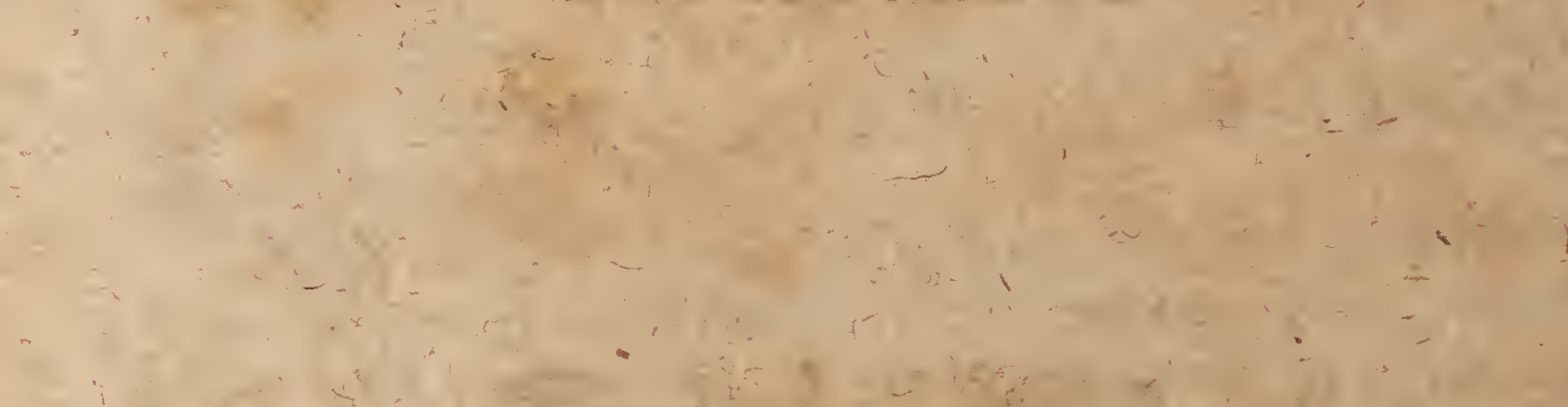

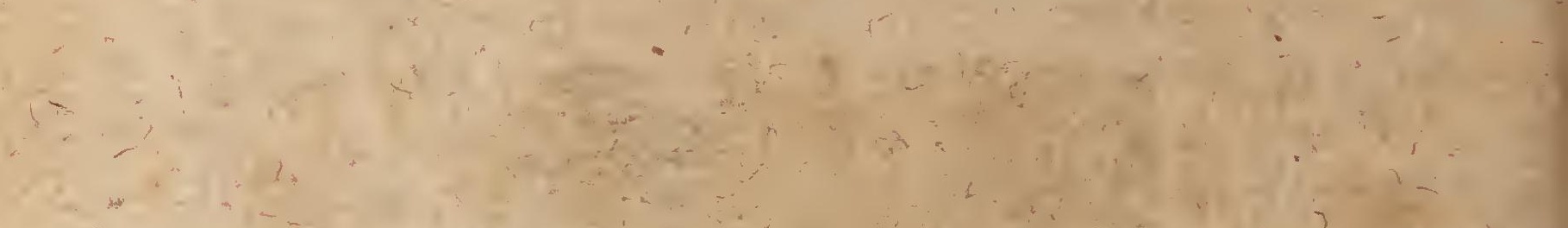

$i$

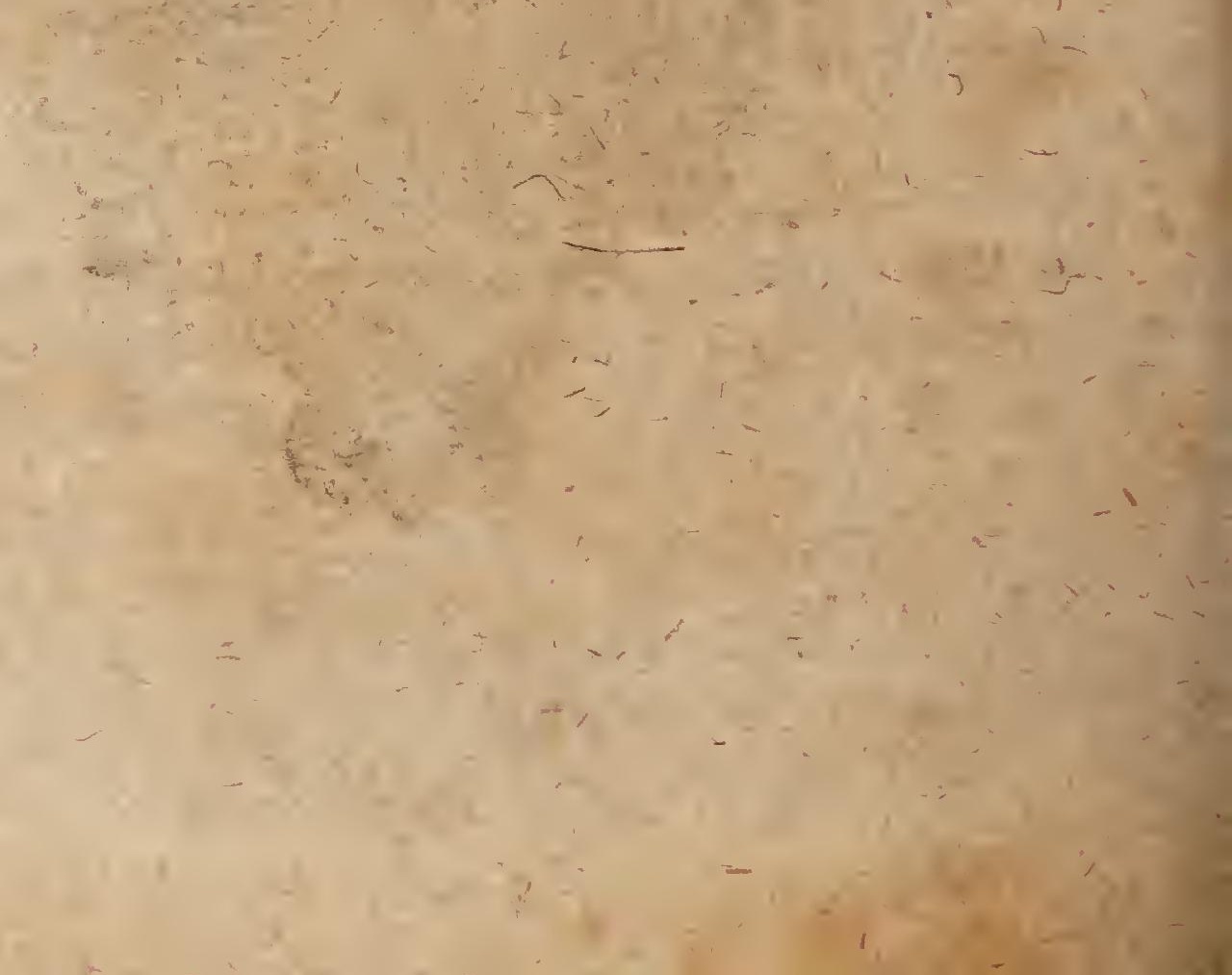

